\title{
Méthodes de dosage des protéines du lait de vache
}

\author{
H. GUILLOU, J.P. PELISSIER et R. GRAPPIN* \\ INRA-CNRZ, Laboratoire de Biochimie et Technologie laitières \\ 78350 Jouy-en-Josas, France \\ * INRA, Station expérimentale laitière - 39800 Poligny, France
}

\section{Résumé}

Un grand nombre de méthodes a été utilisé pour le dosage quantitatif des protéines du lait (protéines totales, caséines, protéines du lactosérum) : méthodes de dosage nécessitant la dégradation par voie chimique des protéines (méthode de Kjeldahl, Dumas, Kofranyi, dosage des acides sialiques), méthodes par titrage à la formaldéhyde, par fixation de colorant, par colorimétrie, par spectrométrie d'absorption dans l'infrarouge et l'ultraviolet ou par fluorescence dans l'ultraviolet, méthodes turbidimétriques, méthodes électrophorétiques, méthodes chromatographiques, méthode immunologiques et par action d'exopeptidases (carboxypeptidase A). Les avantages et les inconvénients de chacune d'elles sont discutés. Leur utilisation en dosage de routine dans l'industrie laitière ou au stade du laboratoire est précisée. Les variantes ou améliorations de chaque méthode, utilisées lors du dosage des protéines du lait sont rapportées de même qu'un certain nombre d'indications (agents de conservation, effet de la saison, de la race, de l'âge ou du stade de lactation...).

Mots clés : Protéines - Lait - Vache - dosage.

\section{Summary}

Methods for the quantitative determination of milk proteins

A great number of methods have been used for the determination of milk proteins (total proteins, caseins, whey proteins): Techniques which necessitate chemical degradation of proteins (Kjeldahl, Dumas, Kofranyi, sialic acid analysis) formaldehyde titration, dye binding, colorimetry, absorption spectrometry in IR and UV range, fluorescence in UV, turbidimetric methods, electrophoretical and chromatographic methods, immunological techniques and action of exopeptidases (carboxypeptidase A). The advantages and drawbacks of each method are discussed. Their use in routine analysis in the dairy industry and laboratory practice is outlined. The modifications and improvements of each method used for milk protein determination are discussed and some indications are given regarding preserving agents, influence of the season, age and stade of lactation.

Key words : Proteins - Milk - Cow - Quantitative determination.

Correspondance : J.P. PÉLISSIER, INRA-CNRZ, Laboratoire de Biochimie et Technologie laitières - 78350 Jouy-en-Josas, France. 


\section{Introduction}

Un des objectifs de la biochimie alimentaire est la séparation et la quantification des différents constituants présents dans les aliments. La séparation permet leur identification ultérieure (nature et fonction des constituants) et la quantification permet de déterminer leur teneur relative.

Suivant le but recherché, la quantification des constituants de la matière sèche peut se faire de deux manières différentes.

Dans la première, les groupes de constituants principaux de l'aliment (lipides, protéines, glucides, sels minéraux) peuvent être quantifiés. Ce type de dosage se fait dans les laboratoires de recherche, mais aussi dans les laboratoires de contrôle de l'industrie alimentaire. Dans le cas du lait, la détermination de la teneur en protéines totales se fait par la méthode du Kjeldahl, par fixation de colorant ou par spectrométrie dans l'infrarouge et l'ultraviolet. La méthode par fixation de colorant (principalement le noir amido) et la spectrophotométrie dans l'infrarouge sont les plus utilisées dans les laboratoires de contrôle de l'industrie laitière. Ces méthodes sont le plus souvent automatisées. Ce sont des méthodes de routine car elles sont simples, rapides, peu onéreuses et peuvent être utilisées par du personnel peu spécialisé. Elles permettent le paiement du lait au producteur selon sa teneur en protéines.

Dans la deuxième, chaque constituant de l'aliment est quantifié (chaque protéine, chaque acide gras...). Ce type de dosage se fait principalement dans les laboratoires de recherches. Appliquées au dosage des protéines du lait, les méthodes utilisées permettent de séparer et de quantifier les différentes protéines. Ce sont principalement les méthodes électrophorétiques, chromatographiques, et immunologiques. La possibilité, ou l'impossibilité, de quantifier chaque protéine dépend du pouvoir de séparation et de la sensibilité de la méthode utilisée.

Le but de cette revue est de présenter les principales méthodes utilisées pour le dosage des protéines du lait. Ces méthodes ont été employées pour doser les protéines du lait de différentes espèces. Nous nous sommes principalement intéressés ici au dosage des protéines du lait le plus utilisé dans l'alimentation humaine : le lait de vache.

\section{Les protéines du lait}

La matière azotée du lait est divisée en deux parties : la matière azotée protéique (correspond à $95 \%$ de l'azote total) et la matière azotée non protéique (NPN). En fonction de leur solubilité à $\mathrm{pH} 4,6$, les protéines du lait peuvent être réparties en deux catégories : les caséines (insolubles à ce $\mathrm{pH}$ ) et les protéines du lactosérum (solubles à pH 4,6) (AlaIs, 1984). 


\section{A. Les caséines ou protéines insolubles à $p H$ 4,6}

La caséine entière représente $80 \%$ des protéines du lait de vache. On ne lui connait pas de fonction biologique autre qu'un rôle nutritif d'apport d'azote et d'acides aminés indispensables. Elle est constituée de 4 caséines $\left(\alpha_{s_{1}}, \alpha_{s_{2}}, \beta, \mathrm{K}\right)$ qui sont synthétisées dans la glande mammaire à partir de 4 gènes de structure différents situés sur le même chromosome (GRosclaudE et al., 1972).

Les caséines $\alpha_{s_{1}}, \alpha_{s_{2}}$ et $\beta$ sont des phosphoprotéines. La caséine $K$ est une phosphoglycoprotéine. Ces protéines sont hétérogènes. Cette hétérogénéité est due à des teneurs différentes en phosphore pour les caséines $\alpha_{s_{1}}$ et $\alpha_{s_{2}}$ ou en sucre pour la caséine K (Ribadeau Dumas, 1979).

Un groupe de « caséines mineures 》 (caséines $\gamma$ ) a été mis en évidence dans le lait de vache, Les 3 caséines de ce groupe $\left(\gamma_{1}, \gamma_{2}, \gamma_{3}\right)$ correspondent aux fragments $29-209,106-209,108-209$ de la caséine $\beta$. Ils proviennent de la protéolyse limitée de la caséine $\beta$ par la plasmine, enzyme provenant du sang et naturellement présentedans le lait (Kaminogawa et YamauchI, 1972). La caséine $\alpha_{s 1}$ est hydrolysée par la plasmine en caséine $\lambda$ (EIGEL, 1977 ; AIMUTIS et EIGEL, 1982). La caséine $\alpha_{s_{2}}$ est également sensible à l'action de cette protéase (SNOEREN et VAN Riel, 1979).

Dans le lait, les caséines sont présentes sous forme d'agrégats de haut poids moléculaire : les micelles. Ce sont des particules sphériques d'un diamètre moyen d'environ $100 \mathrm{~nm}$, constituées elles-mêmes de sous-unités sphériques, appelées submicelles (diamètre moyen de 15 à $20 \mathrm{~nm}$ ), qui renferment les 4 caséines sur lesquelles sont fixés des ions calcium. Les submicelles sont " cimentées » entre elles par le " phosphate colloïdal " qui est un complexe phosphate-citrate de calcium et de magnésium amorphe (SCHMIDT, 1982).

La caséine $K$ stabilise, sous forme de micelles, les autras caséines, normalement insolubles à une teneur en calcium égale à celle du lait. L'action préférentielle de la présure (mélange de protéases extraites de l'estomac du jeune veau nourri au lait, utilisé pour la fabrication fromagère) sur la caséine $K$, en hydrolysant la liaison Phe 105 - Met 106, déstabilise les micelles et entraîne la coprécipitation des caséines $\alpha_{s_{1}}, \alpha_{s_{2}}$ et $\beta$, et de la para-caséine $K$ (fragment 1-105 de la caséine $K$ ) qui sont insolubles à la teneur en calcium du lait. Le caséinomacropeptide ou CMP (fragment 106-169 de la caséine $\mathrm{K}$ ) reste soluble, ainsi que les protéines du lactosérum.

\section{B. Les protéines du lactosérum ou protéines solubles à $p H 4,6$}

Elles représentent $20 \%$ des protéines du lait de vache. Les 2 protéines majoritaires, en poids, sont la $\beta$-lactoglobuline $(44 \%$ des protéines du lactosérum) et l' $\alpha$-lactalbumine ( $20 \%$ ). A côté de ces deux protéines, le lactosérum renferme de très nombreuses autres protéines (BLANC, 1982).

Certaines protéines du lactosérum sont synthétisées dans la glande mammaire ( $\alpha$-lactalbumine, $\beta$-lactoglobuline) et d'autres proviennent du sang (sérum albumine, lysozyme,... ). Ces protéines ont différents rôles. A titre d'exemple, 
la $\beta$-lactoglobuline a un rôle nutritionnel. L' $\alpha$-lactalbumine et la plasmine ont un rôle enzymatique. Les immunoglobulines ont un rôle protecteur. La lactoferrine permet le transport d'ions inorganiques (RIBADEAU-DUMAS, 1979).

Les protéoses peptones représentent une fraction complexe, contenant des fragments de protéines. On y trouve les fragments " 5 lent » (1-105), " 8 lent " (29-107) et « 8 rapide » (1-28) provenant de l'hydrolyse de la caséine $\beta$ par la plasmine. Ces peptides sont les compléments des caséines $\gamma$ (ANDREws, 1979).

L'importance nutritionnelle et la grande diversité des protéines présentes dans le lait expliquent que de nombreuses méthodes de dosage aient été utilisées. Les unes servent à des dosages permettant de repérer et de quantifier un composant particulier. Un certain nombre de ces techniques sont utilisées en routine dans l'industrie alors que d'autres sont utilisées dans les laboratoires de recherches. La grande diversité des techniques utilisées, et la vitesse d'évolution scientifique et technologique de ces techniques, nécessitent d'en faire un bilan périodique. C'est ce que nous avons tenté ici, afin de présenter les grandes lignes des techniques utilisées, sans prétendre à l'exhaustivité. Pour les travaux plus anciens, il est possible de se reporter à la revue de Bosset et al. (1976).

\section{Les méthodes de dosage}

Les méthodes de dosage des protéines du lait, utilisées en routine ou dans les laboratoires de contrôle de l'industrie laitière, fournissent des résultats qui ne sont pas directement comparables, car obtenus par des techniques différentes. La comparaison des résultats obtenus par différentes méthodes ou d'un laboratoire à l'autre, doit être basée sur une méthode de référence commune dont la précision est bonne. La précision est une notion globale qui comprend la fidélité (répétabilité : fait par le même opérateur, dans le même laboratoire ; reproductibilité : comparaison d'un laboratoire à l'autre), la justesse (comparaison d'une méthode à une méthode de référence) et la sensibilité (GRAPPIN, 1976 c).

Pour le domaine alimentaire, la méthode de référence adoptée est la méthode de Kjeldahl. Elle permet ainsi, dans le cas des méthodes de routine, le paiement du lait à la qualité sur la base d'une référence unique. Pour permettre la conversion des résultats obtenus avec une autre méthode, un grand nombre d'échantillons sont analysés par la méthode de référence (y) et par la méthode utilisée (x). D'après les résultats, une droite de régression d'équation $\mathrm{y}=\mathrm{bx}+\mathrm{a}$ est calculée. Elle donne la relation entre la mesure obtenue par la méthode $(\mathrm{x})$ et la teneur en protéines donnée par la méthode Kjeldahl (y). On compare l'équation obtenue avec la droite théorique d'équation $\mathrm{y}=\mathrm{x}$. Il faut que la droite obtenue ne diffère pas trop de la droite théorique pour avoir une bonne exactitude du calibrage. Plus le coefficient de corrélation est proche de 1, meilleure est la précision de la méthode employée, par rapport à la méthode de Kjeldahl.

Avec certaines techniques, les différentes fractions azotées du lait (caséines, protéines du lactosérum, NPN) se comportent différemment lors des 
dosages. Suivant les différentes fractions azotées du lait obtenues par fractionnement chimique, les méthodes peuvent être étalonnées pour doser la matière azotée totale, les protéines totales, les caséines,... Les méthodes de dosage de routine sont généralement étalonnées pour doser la matière azotée totale et les protéines totales. L'étalonnage fait à partir des protéines totales peut être influencé par la variation du rapport des teneurs en protéines solubles et des caséines. Les variations en fonction de la période ont été étudiées par différents auteurs (HARland et al., 1955 ; DEllamonICA et al., 1965 ; GRAPPIN et JEUNET, 1976 a). Le rapport varie beaucoup avec l'individu, la race et le stade de lactation. La précision du dosage des protéines totales sera plus faible pour les laits individuels que pour les laits de mélange dans lesquels ces variations se compensent partiellement.

L'étalonnage fait à partir de l'azote total peut être influencé par la variation de l'azote non protéique (NPN) en fonction de la période et de l'endroit. Cette fraction varie beaucoup avec l'individu, la race, l'alimentation et le stade de lactation. Il faut donc réétalonner fréquemment ou considérer que cette fraction est en moyenne égale à $5 \%$ (GRAPPIN et JEUNET, 1976 a). Si on ajoute les considérations faites précédemment à propos de la variation de la teneur des différentes fractions protéiques du lait, la précision du dosage de l'azote total est plus faible avec les laits individuels qu'avec les laits de mélange.

\section{A. Méthodes de dosage nécessitant la dégradation par voie chimique des protéines}

\section{Méthode de Kjeldahl}

Cette méthode, qui est la méthode de référence, consiste à effectuer une minéralisation complète des molécules organiques, transformant l'azote présent en ammoniaque qui peut être dosé par différentes techniques.

\section{a) Présentation de la méthode}

Les échantillons sont minéralisés en présence d'acide sulfurique concentré et chaud $\left(250^{\circ} \mathrm{C}\right)$. Le carbone, l'oxygène et l'hydrogène sont transformés en gaz carbonique et en vapeur d'eau, alors que l'azote reste en solution sous forme de sulfate d'ammonium. L'adjonction d'acide perchlorique ou d'eau oxygénée permet une minéralisation plus poussée (KRAME et al., 1973), Des catalyseurs doivent être rajoutés au milieu réactionnel (Sélénium, sels de mercure ou de cuivre, le sulfate de cuivre est le catalyseur retenu par la FIL). Les sulfates de potassium ou de fer élèvent le point d'ébullition. L'ammoniaque est obtenu par alcalinisation du milieu. Trois techniques permettent de doser cet ammoniaque. Elles nécessitent la constitution d'une courbe d'étalonnage obtenue avec des solutions de concentration connue en sulfate d'ammonium.

\section{- Le titrage}

L'ammoniaque est titré par un acide $\left(\mathrm{HCl}, \mathrm{H}_{2} \mathrm{SO}_{4}\right)$ après entraînement à la vapeur (distillation) et piégeage dans une solution d'acide para-hydroxybenzoïque ou d'acide borique (URBAN, 1971). La diffusion, technique selon laquelle l'ammoniaque se propage dans la solution piégeante placée dans un container, a aussi été utilisée (LIN et RANDOLPH, 1978). L'ammoniaque augmente 
le $\mathrm{pH}$ de la solution et la quantité d' $\mathrm{HCl}$ rajoutée pour revenir au $\mathrm{pH}$ initial, détectée par l'utilisation d'un indicateur coloré, est proportionnelle à la quantité d'ammoniaque. Le titrage est une méthode manuelle. Il peut être partiellement (LiN et RANDOLPH, 1978) ou totalement automatisé.

- La colorimétrie

Un certain nombre de réactions colorimétriques permettent de doser l'ammoniaque. Parmi les réactifs utilisés nous avons : $\mathrm{Hgl}_{4}$ (réactif de Nessler), la ninhydrine, le phénol hypochlorite (réaction de Berthelot) (BEEcHER et WHITTEN, 1970), le salicylate dichloroisocyanurate (BIETZ, 1974). La sensibilité des réactions de coloration avec ces deux derniers réactifs peut être augmentée par l'adjonction de nitroprussiate (BIETZ, 1974). Il existe une version entièrement automatique de cette méthode qui s'est imposée pour le dosage en flux continu de l'azote (Krame et al., 1973 ; BiEtz, 1974). Avec cette méthode, la hauteur des pics obtenus est proportionnelle à la quantité d'ions ammonium.

- La potentiométrie

L'introduction dans la solution d'une électrode spécifique de l'ammoniaque permet une mesure directe, une fois l'équilibre atteint. La différence des potentiels d'électrodes entre la solution étudiée et une solution étalon permet, à l'aide d'un facteur adéquat, de déterminer la quantité d'azote (DESCHREIDER et Meaux, 1973).

\section{b) Application au dosage des protéines du lait}

Les différentes fractions azotées du lait peuvent être obtenues par fractionnement chimique. La première méthode de fractionnement a été réalisée par Rowland en 1938, et revue par AschaFFENBURg et DREWRY en 1959.

L'azote est dosé par la méthode de Kjeldahl dans les différentes fractions. Parmi les méthodes de dosage de l'ammoniaque, le titrage (LIN et RanDolPH, 1978) et le dosage automatique (KRAME et al., 1973) sont les plus utilisés.

Les diverses protéines lactiques contiennent à peu près toutes la même proportion d'azote (caséine $\alpha_{\mathrm{s1}}: 15,3 \%$, caséine $\alpha_{\mathrm{s} 2}: 14 \%$, caséine $\beta: 15,33 \%$, caséine $\mathrm{K}: 14,5 \%$, $\beta$-lactoglobuline : $15,60 \%$, $\alpha$-lactalbumine : 15,86\%). La transformation des résultats en poids de protéine s'obtient en multipliant la quantité d'azote déterminée par un facteur adéquat : on prend la teneur en azote multipliée par 6,38 ce qui correspond à une teneur de $15,67 \%$. On peut ainsi doser les protéines dans les différentes fractions azotées du lait sauf la fraction non protéique pour laquelle ce coefficient n'est pas valable (CERBULIS et FARRELL, 1975).

\section{c) Problèmes liés à la méthode}

Des problèmes sont directement liés aux méthodes de dosage de l'ammoniaque. La distillation avant le titrage nécessite beaucoup d'attention. La diffusion est une technique trop longue $(2 \mathrm{~h})$ et les résultats obtenus sont moins élevés qu'avec la méthode par distillation (LIN et RANDOLPH, 1978). En colorimétrie, certains facteurs peuvent avoir une influence sur le développement de la coloration : stabilité du pH, choix des tampons (BEecher et WHITten, 1970) présence de certains ions (KRAME et al., 1973). 
Les séparations chimiques ne sont pas parfaites. En partículier, la précipitation à $\mathrm{pH} 4,6$ ne sépare pas parfaitement la caséine entière du lactosérum (Yvon et al., 1984 ; BRIGNoN et al., 1985). Le coefficient multiplicateur de 6,38 n'est pas parfaitement adapté à toutes les fractions (NPN notamment). Toutes les formes d'azote ne sont pas totalement dosées car certaines structures moléculaires sont difficiles à détruire lors de la minéralisation (indole du tryptophane, imidazole de l'histidine).

Tout ceci soulève le problème de la fidélité de la méthode de Kjeldahl, quand on sait que c'est la méthode de référence pour les autres méthodes de dosage des protéines du lait. Cependant, de récents essais effectués au niveau de la FIL montrent que la méthode est fidèle. De plus, la méthode manuelle est longue et fastidieuse, ce qui empêche i'utilisation de cette méthode en routine pour le paiement du lait à sa teneur protéique.

\section{Méthode de Dumas}

La méthode de Dumas est également basée sur le dosage de l'azote protéique par minéralisation poussée des protéines. Cette méthode est plus juste que la méthode de Kjeldahl puisqu'elle permet de doser toutes les formes de l'azote, mais elle est très délicate. Elle fonctionne bien sur des poudres homogènes. Les échantillons doivent de plus être d'un volume très réduit et ne pas contenir trop d'eau. Le lait, du fait de la présence des divers constituants (protéines, matière grasse,...) se prête moins bien à cette technique. Elle a été supplantée par la méthode de Kjeldahl comme méthode de référence.

Dans cette méthode, les substances organiques sont brûlées sous atmosphère d'oxygène dans un circuit fermé. L'excédent d'oxygène est fixé à haute température par de la poudre de cuivre. Les produits de la combustion (vapeur d'eau et gaz carbonique) sont absorbés par une solution concentrée de potasse. Les oxydes d'azote sont réduits, à chaud, par du cuivre en azote moléculaire $\left(\mathrm{N}_{2}\right)$. La teneur en azote moléculaire est mesurée volumétriquement au moyen d'une burette à gaz (MoRris et al., 1968), ou par chromatographie en phase gazeuse.

Le coefficient de 6,38 permet la transformation de la quantité d'azote déterminée en poids de protéine. Les considérations faites à propos de la méthode de Kjeldahl (problèmes de fractionnement chimique, du coefficient, de la durée de la méthode) restent valables pour la méthode de Dumas.

Il existe une version automatique de cette méthode, dont les performances (précision, rapidité d'exécution) sont moins élevées que la version automatique du Kjeldahl (WANG et STONE, 1967 ; MORRIS et al., 1968).

\section{Digestion alcaline et méthode de Kofranyi}

La méthode de Kofranyi repose sur la propriété qu'ont les protéines de libérer une certaine quantité d'ammoniaque, dans un milieu fortement alcalin $(\mathrm{NaOH})$. L'ammoniaque est distillé $(10 \mathrm{~min})$, fixé par une solution d'acide borique et titré par $\mathrm{HCl}$. Le mécanisme de la réaction est mal connu. La validité de la méthode est limitée car toutes les protéines ne possèdent pas le même nombre d'acides aminés susceptibles de libérer de l'ammoniaque. Cette méthode a été appliquée au lait (DyDENKov, 1966). Elle a été utilisée comme 
méthode de dosage de routine. Elle a l'inconvénient d'être coûteuse et n'est, semble-t-il, plus utilisée.

La classique hydrolyse alcaline des protéines suivie d'une réaction de coloration à la ninhydrine a été également utilisée (MC GRATH, 1972).

\section{Méthode par dosage des acides sialiques}

Cette méthode a été utilisée pour doser la caséine $\mathrm{K}$ (les sucres de la caséine $\mathrm{K}$ contiennent des acides sialiques). La caséine entière, obtenue par précipitation à $\mathrm{pH} 4,6$ est hydrolysée $\left(\mathrm{H}_{2} \mathrm{SO}_{4}, 80^{\circ} \mathrm{C}, 45 \mathrm{~min}\right)$. L'hydrolysat est oxydé par l'acide périodique et de l'arsenate de sodium est ensuite rajouté. L'addition d'acide 2 thiobarbiturique (Réactif de Warren) développe une couleur rouge. Le chromophore est extrait à la cyclohexanone. L'absorbance à $549 \mathrm{~nm}$ est proportionnelle à la quantité d'acides sialiques dans l'échantillon de départ. Cette quantité d'acides sialiques est correlée à la quantité de caséine $K$ du lait. Une courbe d'étalonnage est constituée avec des quantités connues d'acides sialiques (MARIER et al., 1963).

Cette méthode ne peut être appliquée au lait entier puisque d'autres composants contiennent des acides sialiques (composant 3 des protéoses peptones) (MARier et al., 1963). De plus, la caséine K est composée de 7 fractions (de $K_{1} \quad \grave{a} K_{7}$ ) ayant des teneurs différentes en acides sialiques. Le résultat. obtenu est donc une teneur globale en sucres de la caséine. Il est peu probable que les différentes fractions de la caséine $K$ (chacune étant supposée avoir une teneur constante en acides sialiques) soient en proportions constantes. II est donc inenvisageable de doser en routine chaque composant de la caséine $\mathrm{K}$ avec cette méthode car leur séparation nécessite une chromatographie (Rose et al., 1969). La caséine entière doit être parfaitement lavée pour éliminer le lactose dont la présence modifie la coloration obtenue (chromophore de couleur orange). Le temps d'hydrolyse doit être parfaitement déterminé. Si ce temps est trop court, tous les acides sialiques ne seront pas libérés. S'il est trop long, une partie des acides sialiques risque d'être dégradée. Une cinétique d'hydrolyse devrait être réalisée avant chaque dosage.

\section{B. Méthode par titrage au formaldéhyde}

\section{Présentation de la méthode}

L'addition de formaldéhyde sur les groupements aminés libres des acides aminés des protéines déplace l'équilibre de dissociation du cation $-\mathrm{NH}^{+}{ }_{3}$ avec libération d'un proton. Il va donc y avoir libération d'une quantité de protons titrables et diminution du $\mathrm{pH}$. Cette variation de $\mathrm{pH}$ sert de mesure.

\section{Application au dosage des protéines du lait}

Cette méthode a été utilisée dans l'industrie laitière comme méthode de dosage de routine (ROEPER, 1974). Appliquée au lait, la technique nécessite quelques améliorations comme l'emploi d'oxalate de potassium qui précipite le calcium, ce qui évite aux phosphates de calcium de réagir avec les protons libérés (Wolschoon et VARgas, 1978). 


\section{Problèmes liés à la méthode}

Le mécanisme complet de la réaction avec le formaldéhyde est mal connu (WolschOON et VARGaS, 1977, 1978). La validité de la méthode est limitée car toutes les protéines ne possèdent pas le même nombre de groupements aminés libres. Cette technique n'est plus utilisée comme méthode de dosage de routine.

\section{Méthode par fixation de colorant (Dye binding)}

\section{Présentation de la méthode}

La méthode consiste à former un complexe coloré insoluble entre un colorant en quantité connue et en excès, et les protéines de l'échantillon. L'excès de colorant non fixé présent dans le surnageant est mesuré spectrométriquement (densité optique à la longueur d'onde d'absorption du colorant) après élimination du précipité par centrifugation ou filtration. Plus la quantité de protéines est grande, plus la densité optique du surnageant est faible. La mesure de la teneur en protéines est indirecte.

Les colorants utilisés sont des acides sulfoniques. Les plus utilisés sont : le Noir Amido 10 B et l'Acide Orange 12. Les groupements sulfoniques des colorants réagissent avec les chaînes latérales des acides aminés basiques (lysine, histidine, arginine), les groupements $\mathrm{N}$-terminaux des protéines, mais aussi avec le colorant déjà lié aux protéines (LAKIN, 1974 ; KROGER et al., 1978). La réaction a lieu en milieu acide (tampon phosphate-citrate de $\mathrm{pH} 2,45$ ). A ce $\mathrm{pH}$, le complexe résulte d'une interaction ionique directe entre l'anion sulfonate du colorant et l'acide aminé basique. L'étalonnage préalable du système avec des solutions de protéines de concentration connue permet le passage de l'absorbance enregistrée à la concentration en protéines.

\section{Application au dosage des protéines du lait} du lait.

C'est la méthode la plus utilisée pour le dosage de routine des protéines

Le colorant le plus utilisé est le Noir Amido 10B (Grappin et Jeunet, 1976 a). L'étalonnage est obtenu en utilisant un grand nombre d'échantillons de lait de mélange.

La méthode peut être manuelle (UDY, 1956), partiellement automatisée (Grappin et al., 1980 ; KwaI Hang et Hayes, 1982 ; Mc Lean et al., 1984) ou entièrement automatisée (GRAPPIN et JEUnET, 1971 ; PARK et KING, 1974). La méthode manuelle a recours à la centrifugation ou à la filtration pour séparer le surnageant du précipité. Les appareils ont recours à la filtration sous pression ou possèdent un dialyseur à flux continu.

\section{Problèmes liés à la méthode}

La filtration est plus utilisée que la centrifugation. Elle est plus rapide et moins onéreuse (coût faible du papier filtre) (SHERBon, 1967), mais l'utilisation du papier filtre absorbe une partie du colorant (AlaIs et al., 1961). L'utilisation de papier en fibre de verre non mouillable permet d'éviter cet inconvénient. 
Le Noir Amido se fixe plus aux protéines que l'orangé G (AlaIs et al., 1961 ; AsworTH, 1966). Le gros problème de ce colorant est sa purification. Deux lots de Noir Amido différents peuvent avoir une absorption différente (AlaIS et al., 1961 ; GRAPPIN et JEUnET, 1976 a). La présence de conservateurs $\left(\mathrm{HgCl}_{2}\right.$, $\mathrm{K}_{2} \mathrm{Cr}_{2} \mathrm{O}_{7}$ ) a une influence sur la coloration. Ces conservateurs entrent en compétition de fixation avec le colorant sur les protéines. Leur concentration, la durée de mise en présence avec le colorant lors du dosage, la température de la réaction, augmentent ou diminuent leur influence. Il en ressort, par exemple, que dans des conditions définies, seul $\mathrm{HgCl}_{2}$ ne modifie pas les mesures avec le Noir Amido dans l'analyse manuelle, et que $\mathrm{HgCl}_{2}$ et $\mathrm{K}_{2} \mathrm{Cr}_{2} \mathrm{O}_{7}$ ne les modifient pas avec les appareils automatiques (GRAPPIN et JEUNET, 1971 ; KWAI Hang et HaYes, 1982).

De nombreux produits laitiers (glaces,...) possèdent des colorants alimentaires. L'absorption de ces colorants à la longueur d'onde du colorant utilisé, va diminuer les résultats du dosage des protéines. Cette diminution sera d'autant plus importante que la bande d'absorption du colorant alimentaire sera proche de celle du colorant fixé. La méthode au Noir Amido est cependant moins affectée que la méthode à l'orangé G. Il est donc recommandé d'appliquer la méthode sur des produits non colorés (KROGER et al., 1978).

Les protéines du lait fixent différemment le colorant. Ainsi les protéines du lactosérum fixent 1,27 fois plus de colorant que les caséines. La fraction azotée non protéique (NPN) ne fixe pas de colorant (AlaIS et al., 1961 ; GRAPPIN et JeUnet, 1979). Cette différence de fixation par les protéines et la variation de la teneur des différentes fractions du lait (suivant la race, l'individu, l'endroit, la saison, le stade de lactation) peuvent avoir une influence sur l'étalonnage de la méthode et le dosage des protéines (Grappin et Jeunet, 1976 a).

La méthode possède une bonne répétabilité (SHERBon et HEMPHILL, 1976; GrapPin et JEUnet, 1971 ; GrapPin et al., 1980). La reproductibilité de la méthode est très bonne. Il y a de faibles écarts entre les différents laboratoires (LUKE, 1967 ; MichilaK et al., 1978). Les performances des appareils de dosage sont identiques à celles de la méthode manuelle (SHERBON, 1974 ; PARK et KING, 1974). L'amélioration de la reproductibilité est encore possible grâce à la mise en place d'un étalonnage commun (Michilak et al., 1978). Cet étalonnage existe en France. Il est réalisé par un laboratoire central qui analyse un nombre élevé d'échantillons provenant de toute la France. On obtient un étalonnage commun qui est « transféré » à tous les appareils par l'intermédiaire de deux échantillons de lait reconstitués de référence, représentant un lait riche et un lait pauvre en protéines, de teneur connue (GRAPPIN et JEUNET, 1976 a).

\section{Méthodes colorimétriques}

1. Méthodes recourant à la formation d'un complexe coloré avec certains acides aminés

Les deux méthodes les plus utilisées sont celles de Folin Ciocalteu (Folin et Ciocalteu, 1927) et de Lowry (Lowry et al., 1951). Ces méthodes consistent en une réaction d'oxydo-réduction entre un réactif phosphomolybdique phosphotungstique et les acides aminés tyrosine et tryptophane des protéines. Le 
développement maximal de la coloration se fait au moyen d'un traitement par une solution alcaline $(\mathrm{NaOH})$ contenant du cuivre $\left(\mathrm{CuSO}_{4}\right)$. L'intensité de la couleur développée, mesurée spectrométriquement, est proportionnelle à la concentration en protéines. Le passage de l'absorbance mesurée à une concentration en protéines se fait par étalonnage avec des échantillons de concentration connue.

Ces méthodes ont l'avantage d'être très sensibles. Elles sont utilisées quand les quantités de protéines de l'échantillon sont extrêmement faibles. Cet avantage ne se justifie pas dans le cas du lait où les quantités de protéines des différentes fractions sont largement suffisantes. De plus, ces méthodes ont des défauts : coloration peu stable, mécanisme de réaction mal connu, dépendance étroite avec la composition en acides aminés des chaînes polypeptidiques, mauvaise corrélation avec la méthode de Kjeldahl (BRown et al., 1983). Ces diverses raisons expliquent le peu de retentissement de ces méthodes appliquées au dosage des protéines du lait (BRown et al., 1983) et leur limitation à des déterminations semi-quantitatives (CHURch et al., 1983).

\section{Méthodes recourant à la formation de complexes colorés avec les liaisons peptidiques}

\section{a) Méthodes du Biuret}

La plus classique de ces méthodes est la méthode de Biuret. La méthode consiste en une réaction entre la liaison peptidique des protéines et un métal de transition ( $\mathrm{Cu}, \mathrm{Ni} . .$.$) pour former un complexe stable et coloré. Cette$ méthode présente un intérêt plus grand pour une détermination quantitative puisqu'elle fait appel à une caractéristique commune à toutes les protéines. Son application au dosage des protéines du lait a fait l'objet de peu de travaux. La méthode est affectée par la teneur en azote non protéique et en matière grasse du lait. La corrélation avec la méthode de Kjeldahl n'est pas très bonne (BRown et al., 1983). La méthode a surtout été utilisée, couplée à un compteur à scintillation.

\section{b) Couplage à un compteur à scintillation}

Cette méthode est basée sur la diminution (quenching) de l'émission photonique indirecte d'une source radioactive constante, placée dans un liquide de scintillation, lorsqu'elle est mise en présence d'une solution colorée. Cette diminution se traduit par une baisse du nombre de coups enregistrés par un compteur à scintillation, dans lequel nous avons deux cuves scellées. Une cuve possède la solution radioactive mélangée à un liquide de scintillation, l'autre cuve possède en plus de ces deux éléments, la solution colorée. L'appareil enregistre la différence du nombre de coups entre les deux cuves qui est proportionnelle à la concentration du complexe coloré (NoBle et al., 1979).

Le liquide de scintillation est une solution organique qui transmet l'énergie radioactive via l'émission photonique. Deux types de sources de radioactivité connue sont utilisées : le cholestérol ${ }^{14} \mathrm{C}$ et l'acide palmitique ${ }^{3} \mathrm{H}$.

Cette méthode a été appliquée au lait (Noble et ScHAND, 1980 ; Noble et al., 1981). Elle permet la détermination quantitative des protéines du lait, mais aussi de la matière grasse et du lactose. Les protéines sont sous forme 
d'un complexe coloré obtenu par la méthode de Biuret. La décroissance du nombre de coups de l'acide palmitique ${ }^{3} \mathrm{H}$ est utilisé pour le dosage des protéines. L'étalonnage permet de transformer le nombre de coups enregistrés en concentration de protéines. Pour le dosage des protéines, l'élimination de la matière grasse est nécessaire pour éviter l'absorption de l'émission photonique.

La méthode possède une très bonne répétabilité et une très bonne précision. Elle a l'avantage de posséder un étalon stable (source radioactive) et la possibilité de détecter, comme toute méthode radioactive, des quantités extrêmement faibles. Les désavantages de la méthode sont principalement : l'utilisation d'isotopes, le problème du bruit de fond dans les mesures, les limites de la méthode du Biuret lorsqu'elle est appliquée au lait et le temps de manipulation qui est plus long que celui des méthodes spectrométriques.

\section{E. Méthodes spectrométriques par absorption et par fluorescence}

Ces méthodes ont longtemps été utilisées pour l'analyse qualitative avant de passer dans le domaine de l'analyse quantitative. Ce sont des méthodes de dosage de routine. Ces méthodes possèdent le grand avantage (sauf dans des cas isolés : fluorescence) de mesurer une propriété intrinsèque des protéines et non un produit de réaction avec ces dernières.

\section{Méthode spectrométrique par absorption dans l'infrarouge}

a) Présentation de la méthode

La plupart des produits organiques possède une absorption dans l'infra. rouge qui se traduit par un accroissement de l'énergie vibrationnelle de la molécule (vibrations de valence et de déformation). On obtient un spectre constitué de nombreux pics d'absorption, correspondant aux divers groupements d'atomes de la molécule. Chaque groupe d'atomes possède une absorption caractéristique à une longueur d'onde donnée. On exprime la longueur d'onde en $\mathrm{nm}$ mais on utilise surtout, pour l'infrarouge, le nombre d'onde $\lambda^{-1}$ en $\mathrm{cm}^{-1}$ pour mesurer l'emplacement d'un pic. L'infrarouge s'étend de 4000 à $600 \mathrm{~cm}^{-1}$. Pour doser les protéines, on met à profit le pic d'absorption de la liaison peptidique à $1548 \mathrm{~cm}^{-1}$. L'intensité du pic suit la loi de Beer Lambert $(\mathrm{Do}=\varepsilon \mathrm{lc})$. La hauteur du pic est donc proportionnelle à la concentration de l'échantillon en protéines. L'étalonnage permet le passage de l'absorbance à une concentration de protéines.

\section{b) Application au dosage des protéines du lait}

Un certain nombre d'appareils ont été conçus pour l'application de la méthode au lait (GouldeN, 1964 ; ADDA et al., 1967, 1968 ; BigGS, 1967, 1972 a et b, 1978, 1979 ; GRAPPIN et JeUNET, 1976 b ; GRAPPIN et al., 1980 ; JoHNSTON, 1982). Ces appareils permettent de doser la matière grasse, le lactose et les protéines du lait. Il suffit de mesurer l'intensité des pics d'absorption à trois emplacements du spectre bien déterminés : matière grasse $\left(1745 \mathrm{~cm}^{-1}\right)$, pro- 
téines $\left(1548 \mathrm{~cm}^{-1}\right)$, lactose $\left(1042 \mathrm{~cm}^{-1}\right)$. Les mesures sont simples et rapides (de 100 à 300 mesures par heure suivant l'appareil).

\section{c) Problèmes liés à la méthode}

Les deux gros problèmes technologiques qu'il a fallu résoudre sont la forte teneur du lait en eau et l'hétérogénéité des globules gras.

L'eau dissout les matériaux utilisés en spectrométrie infrarouge (halogènures de métaux alcalins). Les cuves de mesure ont donc été faites en un matériau très peu soluble. L'eau absorbe une grande quantité d'énergie dans le domaine situé entre 1000 et $5000 \mathrm{~cm}^{-1}$. Les bandes d'absorption de l'eau sont si intenses qu'il est impossible de distinguer les bandes d'absorption des autres composants (Goulden, 1964 ; ADDA et al., 1967, 1968). Pour annuler cette absorption, certains appareils travaillent selon le principe du double faisceau. Une absorption constante due à l'eau est soustraite grâce à une cuve de référence pleine d'eau (GoULDEN, 1964 ; ADDA et al., 1967, 1968). D'autres appareils possèdent un système d'analyse à double faisceau en longueur d'onde. Dans ce système, une longueur d'onde (faisceau de mesure) correspond au pic d'absorption du composé à mesurer et l'autre est une longueur d'onde voisine pour laquelle l'absorption du composé est faible (faisceau de référence). L'appareil mesure la différence d'énergie absorbée par le lait (cuve unique) à chacune des deux longueurs d'onde et l'absorption due à l'eau est ainsi soustraite (Grappin et Jeunet, 1976 b ; Biggs, 1979).

La diffusion de la lumière dépend du rapport entre le diamètre des particules et la longueur d'onde. Or, certains globules gras sont du même ordre de grandeur que les longueurs d'onde utilisées. Il y a alors diffusion de la lumière et atténuation du pic d'absorption. Il faut donc réduire le diamètre des globules gras (moins de $2 \mu \mathrm{m}$ ), à l'aide d'homogénéisateurs, et choisir les bandes d'absorption des composés dans le domaine des grandes longueurs d'onde (donc des petites fréquences). Ainsi, pour la matière grasse, la lecture se fait à $1745 \mathrm{~cm}^{-1}$ et non à $2898 \mathrm{~cm}^{-1}$ (GOULDEN, 1964 ; GRAPPIN et JEUNET, 1976 b). La diffusion due aux micelles de caséines (moins de $0,1 \mu$ ) est négligeable aux longueurs d'onde utilisées (Goulden, 1964).

Les longueurs d'onde sont sélectionnées pour éviter les interférences entre les composés. Il existe cependant une interférence due à la matière grasse à la longueur d'onde des protéines. Une procédure correcte est de corriger la teneur en protéines avec l'aide de la teneur en matière grasse, préalablement déterminée. L'interférence due au lactose, à cette même longueur d'onde, peut être négligée (GOULDEN, 1964). Il est cependant préférable d'utiliser des facteurs de correction pour toutes les longueurs d'ondes.

Les différents appareils possèdent une précision et une répétabilité identiques. Elles sont identiques à celles obtenues pour la méthode par fixation de colorant, lorsque l'étalonnage de l'appareil est soigneusement contrôlé par les utilisateurs (GRAPPIN et JEUNET, 1976 b ; GRAPPIN et al., 1980). Cette méthode possède, elle aussi, une meilleure précision dans le cas des laits de mélange que dans le cas des laits individuels (GRAPPIN et JEUNET, 1976 a). L'explication des variations observées avec la méthode infrarouge n'est 
pas parfaitement déterminée (GRAPPIN et JEUNET, 1976 a). Les variations de la teneur du lait en citrate seraient le principal responsable des écarts observés.

La reproductibilité de la méthode est bonne entre laboratoires (BIGGS, 1978). La mise en place d'un étalonnage commun des appareils, comme pour la méthode par fixation de colorant, a considérablement amélioré la reproductibilité des mesures.

Nous assistons actuellement, au développement des techniques de mesure dans le proche infrarouge. Ces techniques sont rapides et précises (EgLI et Mеунаск, 1984). Elles commencent à se développer dans le domaine laitier, mais peu de publications existent encore sur cette méthode.

\section{Méthode spectrométrique par absorption dans l'ultraviolet}

Cette méthode de dosage repose sur la propriété qu'ont les acides aminés aromatiques (tyrosine, tryptophane et, dans une moindre mesure, phénylalanine) d'absorber de la lumière dans l'ultraviolet. La méthode nécessite un spectrophotomètre sensible.

Cette méthode a été appliquée pour le dosage des protéines du lait. Elle a souvent été utilisée pour doser la teneur en protéines et en matière grasse du lait. L'intensité du pic d'absorption à $280 \mathrm{~nm}$ est proportionnelle à la teneur en protéines.

La méthode présente de nombreux problèmes. Les diverses protéines ont des teneurs différentes en acides aminés aromatiques. L'absorption U.V. des protéines est donc différente, ce qui entraîne une mauvaise corrélation avec la méthode de Kjeldahl, principalement pour les laits individuels (HudsoN et LuCAS, 1983).

La spécificité de la méthode est limitée par l'absorption d'autres composants comme les acides nucléiques.

L'échantillon de lait ne peut être utilisé tel quel à cause de son extrême turbidité. L'échantillon doit être fortement dilué. Les globules gras et les micelles de caséines diffusent la lumière aux longueurs d'onde utilisées. Plusieurs techniques ont été proposées pour les éliminer. Certains auteurs ajoutent à l'échantillon de la butylamine pour éliminer les globules gras et de l'EDTA (avec du lauryl sulfate de sodium) pour dissoudre les micelles de caséines. L'échantillon est filtré, puis on mesure la densité optique à $280 \mathrm{~nm}$ dans le filtrat (NAKAI et al., 1964). D'autres ont recours à la dissolution intégrale des protéines et de la matière grasse de l'échantillon avec de l'acide acétique glacial à $97 \%$. La solution obtenue est claire et incolore. Cette technique permet la mesure correcte de l'absorbance des protéines à $280 \mathrm{~nm}$. En rajoutant au milieu, un mélange d'urée et d'imidazole, la teneur en matière grasse peut être déterminée par simple mesure à $400 \mathrm{~nm}$ (NAKAI et CHILE, 1970). D'autres auteurs recourent à une cellule photoélectrique à géométrie particulière et équipée d'un dispositif permettant de compenser dans une certaine mesure cette diffusion lumineuse (IwaIDA et al., 1967).

\section{Méthode photométrique par fluorescence dans l'ultraviolet}

Lorsqu'une molécule aromatique reçoit de l'énergie (lumineuse ou thermique), il y a transition d'un électron de l'orbitale électronique la plus basse 
(état fondamental : $\mathrm{S}_{0}$ ) vers l'orbitale électronique plus élevée (état excité). Lorsque la molécule se désactive, l'électron revient à son état fondamental et il y a émission d'une radiation lumineuse (photoluminescence). La fluorescence est due au retour de l'électron du premier état singulet $\left(\mathrm{S}_{1}\right)$ vers l'état fondamental $\left(\mathrm{S}_{0}\right)$. L'intensité de la fluorescence est enregistrée par un fluorimètre. 2 types de méthodes fluorimétriques ont été utilisées pour doser les protéines Une de ces méthodes utilise la propriété qu'ont les acides aminés aromatiques des protéines (tyrosine, tryptophane) d'absorber de l'énergie lumineuse à $278 \mathrm{~nm}$ et de la réémettre sous forme de fluorescence à $340 \mathrm{~nm}$. L'autre méthode consiste en l'utilisation de fluorophores (molécules organiques émettant de la fluorescence à une longueur d'onde donnée, qui se fixent sur les protéines). Dans les deux méthodes, l'intensité de la fluorescence est proportionnelle à la concentration en protéines. Ces deux types de méthode ont été appliqués au lait. Un étalonnage préalable permet de transformer l'intensité de fluorescence en concentration de protéines.

\section{phores \\ a) Méthode photométrique par fluorescence sans utilisation de fluoro-}

Cette méthode a été appliquée pour doser les protéines du lait (Fox et al., 1963 ; PoRTER, 1965). Plusieurs facteurs peuvent influencer les mesures de fluorescence. Contrairement à la méthode spectrométrique dans l'ultraviolet, la matière grasse n'a aucune influence sur les mesures. Les micelles de caséines doivent cependant être dissoutes (tampon phosphate citrate urée) car leur présence augmente l'intensité de la fluorescence (Fox et al., 1963). L'échantillon doit aussi être dilué. La température doit être fixe. Une augmentation de la température est à l'origine d'une diminution de la fluorescerice. Le pH doit être fixe ( $\mathrm{pH}$ 6,8) pour éviter l'agrégation des protéines entraînant une augmentation de la fluorescence. Certains ions $\left(\mathrm{Ca}^{++}\right)$et certaines molécules organiques peuvent diminuer l'intensité de la fluorescence. Les ions métalliques peuvent être éliminés par des chélateurs de métaux (citrate d'ammonium qui piège le $\mathrm{Ca}^{++}$...) (Fox et al., 1963).

Comme la méthode spectrométrique dans l'ultraviolet, la méthode dépend du nombre d'acides aminés aromatiques des différentes protéines, ce qui entraîne une mauvaise corrélation avec la méthode de Kjeldahl, principalement dans le cas des laits individuels. La limitation de la précision de la méthode et le nombre important de précautions à prendre, font que cette méthode fluorimétrique est peu utilisée pour le dosage quantitatif des protéines du lait (Fox et al., 1963).

b) Méthode photométrique par fluorescence avec utilisation de fluorophores

Les fluorophores qui ont été utilisés pour le dosage quantitatif des protéines du lait sont l'o-phthaldialdéhyde et la fluorescamine. L'intensité de fluorescence se mesure à $340 \mathrm{~nm}$ et à $480 \mathrm{~nm}$, respectivement (BEEBY, 1980 ; CHURCH et al., 1983).

L'o-phthaldialdéhyde (OPA) réagit avec le groupement $\alpha$ aminés libres des protéines et avec le groupement $\varepsilon$ aminé de la lysine en présence de 2-mercaptoéthanol, pour donner un groupement fluorescent (CHuRcH et al., 1983). La fluorescamine est un fluorophore intéressant car il ne réagit qu'avec 
les groupements $\alpha$ aminés des protéines à $\mathrm{pH} 6$ (BeEBY, 1980). Cette méthode est donc plus précise que la première (OPA), qui est limitée par la teneur différente en lysine des diverses protéines.

\section{F. Méthodes turbidimétriques}

Deux méthodes de dosage de la teneur des protéines du lait (spectrométrique et néphélémétrique), basées sur la turbidité de ces protéines dans certaines conditions, sont utilisées pour le dosage des protéines du lait.

\section{Méthode spectrométrique}

Cette méthode a été utilisée pour la détermination de la quantité des caséines $\alpha_{\mathrm{s}}, \beta$ et $\mathrm{K}$ du lait (Tessier et al., 1963). Beaucoup d'observations ont montré que le degré d'agrégation des caséines $\alpha, \beta$ et $\kappa$ sous forme de micelle est influencé par la température. Les teneurs en caséines $\beta$ et $\mathrm{K}$ affectent la turbidité. La relation entre la somme des deux caséines $(\beta+K)$ et le changement de turbidité de la solution avec la température, permet de déterminer les quantités de ces différentes caséines. La méthode consiste à mélanger une quantité de caséine entière (obtenue par précipitation à $\mathrm{pH} 4,6$ ) avec un tampon imidazole contenant du calcium. La différence des densités optiques à $400 \mathrm{~nm}$ de la solution, mesurées à $0^{\circ} \mathrm{C}$ et à $35^{\circ} \mathrm{C}$ est proportionnelle à la quantité de caséine $\beta$ plus de caséine $K$. Cette quantité est déterminée grâce à la constitution d'une courbe étalon obtenue avec des quantités de caséine $\beta$ et caséine $\mathrm{K}$ connues. La méthode de dosage des acides sialiques permet de déterminer la quantité de caséine $\mathrm{K}$. Connaissant la quantité de caséine totale déterminée préalablement, les quantités de caséine $\alpha . s, \beta$ et $\mathrm{K}$ sont obtenues par différence. Les quantités de $\mathrm{Ca}^{++}$et de caséine entière, le $\mathrm{pH}$ de la solution (entre 6 et 8 ) sont choisis de façon à avoir une augmentation de la turbidité maximale entre $0^{\circ} \mathrm{C}$ et $35^{\circ} \mathrm{C}$. Cette méthode nécessite beaucoup de précautions. La détermination de la teneur en caséine $\beta$ est limitée par la présence de caséines $\gamma$ dont la teneur n'est pas déterminée par cette méthode.

\section{Méthode néphélémétrique}

La néphélémétrie est la mesure de la lumière dispersée par des particules (colloïde). Un faisceau lumineux monochromatique de grande intensité est émis. Le cône de lumière est recueilli après focalisation sur un photodétecteur et le signal électrique, mesuré en volts, est directement proportionnel à la turbidité de la solution. Le néphélémètre est l'appareil responsable de toutes ces opérations. Cette méthode a été appliquée pour doser les protéines et la matière grasse du lait (BEITz et al., 1977). L'appareil est étalonné pour 0 et $100 \%$ de turbidité par une solution de formazine. L'établissement, par étalonnage, d'une droite de régression permet de transformer le pourcentage de turbidité donné par l'appareil en concentration de protéines. Les protéines du lait forment une solution collö̈dale par réaction avec un mélange d'acide acétique glacial, d'anhydride acétique, et d'acide para-toluène sulfonique. La mesure turbidimétrique est alors effectuée. Le colloïde de protéines est ensuite 
dissous. Il peut alors y avoir agrégation de la matière grasse (émulsion), dont la mesure turbidimétrique peut aussi être effectuée.

La méthode est simple, rapide, peu onéreuse. Elle jouit d'une bonne répétabilité et d'une bonne précision. Elle possède tous les critères d'une méthode de dosage de routine, mais elle a été peu utilisée.

\section{G. Méthodes électrophorétiques}

\section{Présentation de la méthode}

L'électrophorèse est la migration de molécules chargées, en solution, sous l'action d'un champ électrique. Les protéines, qui comportent des groupes chargés positivement ou négativement, possèdent une charge globale non nulle sauf à leur $\mathrm{pH}$ iso-électrique, $\mathrm{pH}$ auquel ces charges se compensent exactement. Si l'on place une protéine dans un champ électrique, elle va donc migrer selon sa charge globale nette et sa taille moléculaire soit vers l'anode soit vers la cathode, et d'autant plus vite que cette charge est élevée. La migration se fait sur des supports variés : gels, principalement d'amidon, de polyacrylamide, d'agarose ou de polyacrylamide agarose ; ou, moins fréquemment pour les protéines, papier, acétate de cellulose. Les gels d'électrophorèse peuvent être moulés entre deux plaques de verre ou dans des tubes. Les gels peuvent avoir des porosités différentes suivant leur concentration en polyacrylamide. Plus la porosité du gel est faible (pourcentage d'acrylamide élevé), plus la migration des protéines de poids moléculaire élevé est ralentie. On peut modifier la charge nette de la protéine

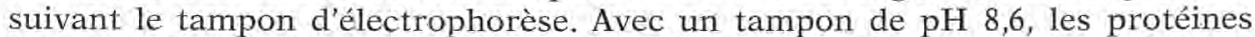
majeures du lait ont une charge nette négative et migrent alors vers l'anode. On utilise généralement un tampon Tris contenant de l'urée (rupture des liaisons hydrogènes) et du 2-mercaptoéthanol (rupture des ponts disulfures) de manière à obtenir une parfaite dissociation des différentes protéines. Les échantillons sont mis en solution dans le tampon, à une concentration finale connue, avant d'être déposés sur le gel.

Le gros avantage de la méthode électrophorétique est de permettre à la fois de séparer et de quantifier les différentes protéines d'un mélange. La quantification des protéines nécessite leur coloration par le bleu de Coomassie ou le Noir amido. La coloration est ensuite enregistrée à l'aide d'un densitomètre à la longueur d'onde correspondant à l'absorption du colorant. Un tracé densitométrique est obtenu et la quantité de chaque protéine est proportionnelle à la surface de chaque pic. Cette méthode nécessite la constitution d'une gamme étalon obtenue avec une quantité connue de chacune des protéines.

\section{Application au dosage des protéines du lait}

Les différentes techniques électrophorétiques mentionnées précédemment, ont été appliquées au dosage quantitatif des caséines et des protéines du lactosérum. L'électrophorèse sur papier (BORTREe et al., 1962 ; SHAH et Morse, 1964), l'électrophorèse sur gel en plaque (HAENLEIN et al., 1973 ; RANDOLPH et al., 
1974 ; KWaI-Hang et Kroeker, 1984 ; Mc Lean et al., 1982, 1984 ; Basch et al., 1985) et sur gel en tube (Dill et al., 1972 ; NaGaSawa et al., 1972, 1973).

\section{Problèmes liés à la méthode}

La préparation du gel (polymérisation, moulage et démoulage, équilibrage dans un tampon) dure plusieurs heures. La migration électrophorétique ainsi que la coloration durent 2 à $3 \mathrm{~h}$. L'électrophorèse est une technique longue. Elle ne peut donc pas être utilisée comme méthode de dosage de routine des protéines du lait. L'électrophorèse sur gel d'acétate de cellulose est rapide (15 min) mais n'a pas été appliquée au dosage quantitatif des protéines du lait.

Lors d'une électrophorèse sur gel en tube, les échantillons de la gamme étalon, contrairement à l'électrophorèse en plaque, sont placés dans des tubes différents. La précision du dosage peut être limitée par la différence de porosité des gels.

La coloration de certaines protéines présentes en trop faible quantité est difficile malgré la sensibilité des colorants (cas des caséines $\alpha_{s 2}$ ). Les différentes protéines ne fixent pas la même quantité de colorant. L'étalonnage doit donc être fait avec des protéines pures.

\section{H. Méthodes chromatographiques}

Comme l'électrophorèse, les méthodes chromatographiques permettent la séparation et la quantification des différentes protéines d'un mélange. La chromatographie sur DEAE cellulose, sur hydroxyapatite et par filtration sur gel sont des méthodes longues, pouvant difficilement être utilisées pour des dosages de routine. Le développement des techniques chromatographiques rapides comme la FPLC (Fast Protein Liquid Chromatography) et la HPLC (High Pressure Liquid Chromatography) suscitent dans ce domaine de nombreux espoirs (abaissement des temps d'analyse, sensibilité accrue).

\section{Chromatographie sur DEAE cellulose}

Cette méthode consiste à fixer les protéines par l'intermédiaire de leurs charges négatives, sur les charges positives de la colonne de DEAE cellulose (interactions électrostatiques). Comme en électrophorèse, le tampon utilisé (tampon imidazole de $\mathrm{pH}$ 7) contient de l'urée et du 2-mercaptoéthanol permettant une bonne séparation des protéines. Certains auteurs (Rose et al., 1969; Davies et LAW, 1977 a) rajoutent de l'iodacétamide. L'iodacétamide permet l'alkylation des fonctions thiols des cystéines, évitant ainsi leur réassociation ultérieure. Une fois fixées sur la colonne, les différentes protéines sont éluées, par le même tampon, mais de concentration croissante en $\mathrm{NaCl}$. Plus la charge nette de la protéine est négative, plus la concentration de $\mathrm{NaCl}$ nécessaire pour l'éluer est élevée. L'absorbance à $280 \mathrm{~nm}$ est mesurée pour obtenir un profil d'élution dans lequel chaque pic a été identifié par électrophorèse lors de la mise au point de la technique. Si le pic correspond à une seule protéine, l'aire de ce pic est proportionnelle à sa concentration. Connaissant $l^{\prime} \varepsilon$ molaire de chaque protéine, leur concentration peut être obtenue directe- 
ment à partir du profil d'élution par application de la loi de Beer Lambert $\left(\mathrm{D}_{0}=\varepsilon_{280} \mathrm{cl}\right)$ (Rose et al., 1969) ou après coloration des différentes fractions éluées par la méthode de Biuret et mesure de la densité optique à $310 \mathrm{~nm}$ (DAvies et LAW, 1977 a).

Cette méthode a été appliquée pour le dosage des caséines (Mercier et at., 1968 ; Rose et al., 1969 ; DAvies et LAw, 1977 a, b, 1980). 5 fractions sont obtenues par ordre d'élution : les caséines $\gamma$, les caséines $K$, la caséine $\beta$, les caséines $\alpha_{\mathrm{S2}}\left(\alpha_{\mathrm{si}}, \alpha_{\mathrm{S4}}, \alpha_{\mathrm{S} 3}\right.$ et $\left.\alpha_{\mathrm{S} 2}\right)$ et les caséines $\alpha_{\mathrm{si}}$. Les résultats obtenus montrent une bonne répétabilité de la méthode. La précision des dosages est limitée pour certaines fractions. Les protéoses peptones sont éluées avec les caséines $\alpha_{s}$ (Rose et al., 1969). Le dosage des caséines $\mathrm{K}$ fournit une surestimation de leur teneur, due à la contamination de cette fraction par des protéines non identifiées (DAvies et LAW, 1977 a, b, 1980).

\section{Chromatographie sur hydroxyapatite}

Cette méthode consiste en l'adsorption, par l'hydroxyapatite, des protéines par l'intermédiaire de leurs charges négatives. Le tampon utilisé est un tampon phosphate de $\mathrm{pH}$ 6,8 contenant du dithiotréitol et de l'urée. Plus la charge nette de la protéine est négative, plus elle est retenue lors de l'élution qui se fait avec le tampon phosphate à des concentrations croissantes en phosphate. Un profil d'élution est obtenu par mesure de l'absorption de l'éluat à $280 \mathrm{~nm}$. Une électrophorèse permet, là aussi, d'identifier les différents pics. Connaissant $l^{\prime} \varepsilon$ molaire de chaque protéine, leur concentration est obtenue directement par application de la loi de Beer Lambert $\left(D_{0}=\varepsilon_{280} \mathrm{cl}\right.$ ) (BARRY et DONNELLY, 1979, 1980).

Cette méthode a été appliquée pour le dosage des caséines (ADDEo et al., 1977; Donnelly, 1977; Barry et DonNelly, 1977, 1980), et pour le dosage des protéines du lait écrémé (BARRY et DonNELly, 1979). La caséine entière est éluée en 4 fractions : les caséines $\gamma$, les caséines $K$, la caséine $\beta$ et les caséines $\alpha$. Contrairement à la chromatographie sur DEAE cellulose, cette méthode ne permet pas de séparer les caséines $\alpha_{\mathrm{s}}$ en deux fractions. La précision est limitée par la contamination de la fraction de la caséine $\beta$ par les caséines $\alpha$ s. La fraction contenant les caséines $\alpha$ s est contaminée par la caséine $\beta$ et des composés mineurs (protéoses peptones) (DonNelly, 1977). Le profil d'élution obtenu avec le lait écrémé donne aussi 4 fractions. Les caséines $K$ sont éluées avec les protéines majoritaires du lactosérum ( $\alpha$-lactalbumine, $\beta$-lactoglobuline, sérum albumine). L'impossibilité de les séparer empêche leur quantification.

\section{Chromatographie par filtration sur gel}

Le principe de la filtration sur gel est basé sur les capacités différentes des protéines à pénétrer dans les pores de la phase stationnaire (gel). La taille des pores du gel limite un domaine de fractionnement. Les protéines ayant une taille moléculaire supérieure à la taille des pores sont totalement exclues du gel qu'elles traversent rapidement. Elles sont éluées dans un volume appelé volume mort. Les protéines ayant une taille moléculaire inférieure, entrent dans les pores du gel et parcourent un chemin d'autant plus long que 
leur poids moléculaire est petit. Les protéines sont donc éluées dans l'ordre des masses moléculaires décroissantes. Un profil d'élution est obtenu par mesure de l'absorbance de l'éluat à $280 \mathrm{~nm}$. Une électrophorèse permet l'attribution de chaque pic du profil aux différentes protéines.

Cette méthode a été appliquée pour le dosage des protéines du lactosérum (Davies et Law, 1980). L'élution se fait avec un tampon phosphate de pH 6,8. Ces auteurs ont quantifié les protéines après coloration des fractions éluées par la méthode du Biuret et mesure de la densité optique. Seules la B-lactoglobuline, l' $\alpha$-lactalbumine, le sérum albumine et la lactoferrine ont pu être dosées.

Cette méthode possède des limites. Les protéines du lactosérum sont obtenues par filtration après précipitation des caséines à $\mathrm{pH} 4,6$. La quantité d' $\alpha$-lactalbumine et de $\beta$-lactoglobuline qui précipite avec la caséine n'est pas dosée (Yvon et al., 1984). La B-lactoglobuline est cependant surestimée par suite de la contamination de cette fraction par le composant 5 des protéoses peptones.

\section{Chromatographie rapide}

\section{a) FPLC (Fast Protein Liquid Chromatography)}

Dans le cas du lait, cette méthode consiste à séparer les différentes protéines d'un mélange sur une colonne échangeuse d'anions. Le principe et les limites de la méthode sont identiques à ceux de la chromatographie " classique » sur DEAE cellulose. Le gros avantage de cette méthode est que la séparation des différentes protéines est très rapide. La séparation des caséines du lait dure $30 \mathrm{~min}$ au lieu de plusieurs heures (Humphrey et Newsome, 1984 ; BARREFORS et al., 1985).

\section{b) HPLC (High Pressure Liquid Chromatography)}

En HPLC, on peut distinguer suivant la polarité de la phase stationnaire, deux modes de travail : phase normale et phase inverse.

En phase normale, la phase stationnaire est polaire. Les composés sont donc élués par ordre de polarité croissante. Cette phase n'est pas utilisée pour la séparation des protéines.

En phase inverse, la phase stationnaire est apolaire (colonne de silice possédant des groupements alkyle de longueur variable). Cette phase est utilisée pour la séparation, en fonction principalement de leur hydrophobicité, et la quantification des protéines d'un mélange. Les protéines sont éluées par ordre de polarité décroissante par un gradient de concentration en solvant organique. On obtient un profil d'élution par mesure de l'absorbance à $280 \mathrm{~nm}$ de l'éluat. L'identification des différents pics de protéine se fait par injection des protéines pures. Si leur concentration est connue, on peut déterminer l' $\varepsilon$ molaire des différentes protéines, ce qui permet de calculer directement, à partir du profil d'élution, la concentration inconnue des différentes protéines. Cette méthode a été utilisée pour le dosage des protéines du lait ; seules quelques protéines du lactosérum ( $\alpha$-lactalbumine, $\beta$-lactoglobuline, sérum albumine) ont été dosées (PeArce, 1983). La méthode est très sensible et le temps d'analyse est de $30 \mathrm{~min}$. 


\section{Méthodes immunologiques}

\section{Principe des dosages immunologiques}

Un antigène (protéine ou autre macromolécule) et des anticorps (protéines) dirigés contre celui-ci sont susceptibles de s'unir spécifiquement dans des conditions déterminées en formant un précipité. La réaction antigène (AG) + anticorps $(\mathrm{AC}) \longrightarrow \rightarrow$ AG-AC est un équilibre tel qu'il y a dissociation du précipité (AG-AC) en excès d'anticorps ou d'antigènes. Elle est à la base des techniques immunologiques.

Un antigène purifié injecté dans un organisme provoque de la part de celui-ci, la synthèse d'anticorps spécifiques. L'immunsérum monospécifique obtenu est utilisé dans les méthodes d'immunologie quantitative. Le problème est donc de préparer des antigènes suffisamment purs permettant d'obtenir des immunséra monospécifiques. La vérification de la pureté de l'antigène avant injection dans l'animal se fait à l'aide d'anticorps polyspécifiques, dirigés contre toutes les protéines susceptibles de contaminer la préparation. Ces méthodes nécessitent le titrage du sérum. On détermine ainsi la quantité minimale de sérum nécessaire pour obtenir des résultats exploitables. Avec ces méthodes aucun traitement préalable de la solution d'antigène n'est nécessaire, en général, si ce n'est une dilution.

Un courbe étalon est obtenue en utilisant différentes concentrations de l'antigène à doser. La plupart de ces méthodes sont trop longues et trop lourdes pour pouvoir être utilisées comme méthodes de dosage de routine des protéines du lait.

\section{Méthodes immunologiques en milieu gélose}

On a ici recours à la constitution d'un gel (Agarose) auquel est mélangé le sérum monospécifique de concentration connue et préalablement titré. La formation du précipité AG-AC est révélée par coloration (Bleu de Coomassie, Noir Amido). L'ensemble de ces méthodes possède une très bonne répétabilité et elles sont très sensibles (détection de quantités de l'ordre du ng) (BавалтMOPOUlos et MiKolajcik, 1977).

a) Immunodiffusion simple (Méthode d'Oudin)

Le gel obtenu est coulé dans des tubes verticaux. Une solution contenant l'antigène à doser est déposée à sa surface. Cet antigène va migrer (72 h) par diffusion dans le gel jusqu'à ce qu'il y ait formation du précipité. Plus la quantité d'antigène est grande, plus la distance entre le précipité et la surface du gel est grande. Cette distance est proportionnelle à la quantité d'antigène. Cette méthode a été appliquée pour le dosage de la sérum albumine et de la

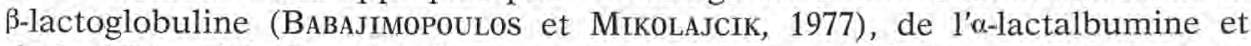
de la $\beta$-lactoglobuline (Mc LEAN et al., 1984). Les principaux problèmes de la méthode sont : l'utilisation de plusieurs tubes dont les gels peuvent avoir des porosités différentes. Certaines distances de migration sont trop petites et peuvent entraîner des erreurs de mesure.

b) Immunodiffusion radiale (Méthode de Mancini)

Dans cette méthode (Mancini et al., 1965), les solutions d'antigène sont placées dans des puits creusés dans un gel horizontal. La migration se fait 
donc sur le même support. La migration de l'antigène par diffusion radiale dans le gel va créer un halo de précipitation : plus la quantité d'antigène est grande, plus la surface du halo de précipitation est grande. Cette surface est proportionnelle à la quantité d'antigène. La méthode a été appliquée pour doser la sérum albumine et la B-lactoglobuline du lait (BABAJIMOPOULos et Mikolajcik, 1977), l'o-lactalbumine (Forsum, 1976), les immunoglobulines $G$ (Lebreton et al., 1981 ; Joisel et al., 1981). Cette méthode est la plus longue de toutes (plusieurs jours). Les erreurs de mesure de la surface des halos sont minimisées par l'utilisation d'un appareil lecteur agrandisseur.

c) Electroimmunodiffusion (Méthode de Laureli)

La grande différence de cette méthode (LAURELl, 1966), avec la méthode de Mancini, est que l'antigène va migrer sous l'action d'un champ électrique. Il va y avoir formation d'un cône de précipitation (appelé aussi "roquette ») dont la hauteur est proportionnelle à la quantité d'antigène. Plus la quantité d'antigène est grande, plus la hauteur du cône de précipitation est grande. Cette méthode a été appliquée au dosage de la caséine $K$ dans les mélanges protéiques complexes (Driou et al., 1985), de la sérum albumine (BABAJImopoulos et Mikolajciк, 1977 ; Sмith et al., 1979), de la ß-lactoglobuline du lait (BABajimopoulos et Mikolajcik, 1977), de la lactoferrine (Schanbacher et Smith, 1974 ; LoNNERdal et al., 1976). Cette méthode est bien plus rapide que les deux autres (quelques heures). L'utilisation d'un gel d'acétate de cellulose permet d'augmenter la rapidité ( $2 \mathrm{~h}$ ) (Schanbacher et Smith, 1974). La mesure de la hauteur des pics est précise pour des pics compris entre 2 et $5 \mathrm{~cm}$.

\section{Méthodes immunologiques avec marquage de l'anticorps ou de l'antigéne}

Les méthodes immunologiques en milieu gélosé exigent des quantités d'antigène et d'anticorps (pour l'imprégnation du milieu gélosé) importantes. On assiste à une orientation préférentielle vers les méthodes utilisant le marquage des antigènes ou des anticorps par fixation d'entités radioactives ou dotées d'une activité enzymatique. Les quantités d'anticorps ou d'antigène utilisées sont moins importantes. Le problème général de ces méthodes est que la fixation de l'entité radioactive ou enzymatique peut modifier l'association antigène-anticorps, en se fixant sur les déterminants antigéniques de l'antigène ou de l'anticorps. Ces méthodes possèdent une très bonne répétabilité et une sensibilité plus élevée (de l'ordre du ng, voire du pg) que celle des méthodes immunologiques en milieu gélosé (BEck et Tucker, 1977 ; MASSEYEF, 1978).

\section{a) Dosage radioimmunologique}

L'antigène étudié est marqué par un isotope radioactif (iode radioactif). Ce dosage est fondé sur l'équilibre de dissociation du complexe antigèneanticorps et sur l'hypothèse que l'antigène chaud (radioactif) et l'antigène froid (non radioactif) se fixent de la même façon sur l'anticorps. L'antigène marqué va permettre la constitution de complexes anticorps-antigène marqués dont une quantité connue est placée dans un tube. Une quantité d'antigène froid est alors rajoutée. Après incubation, le précipité est récupéré par centrifugation et la radioactivité mesurée par un compteur à scintillation. Plus la radioactivité du précipité est faible, plus la concentration d'antigène froid est importante. La radioactivité enregistrée est inversement proportionnelle à la concen- 
tration d'antigène froid de la solution. Cette méthode a été appliquée pour le dosage de l' $\alpha$-lactalbumine et de la prolactine (protéohormone) du lait (BEcK et TUCKER, 1977). Le gros problème de la méthode est l'ensemble des contraintes liées à l'utilisation d'isotopes radioactifs (MASSEYEF, 1978).

\section{b) Dosage immunoenzymatique}

Le principe de cette méthode (MASSEYEF, 1978) est identique à celui du dosage radioimmunologique sauf que le marquage isotopique est remplacé par un marquage enzymatique. L'activité de l'enzyme doit être conservée après sa fixation sur l'antigène qui se fait en général par l'interposition du glutaraldéhyde dont les fonctions aldéhydes réagissent avec la lysine de la protéine. Les enzymes les plus utilisés sont la peroxydase de Raifort et la phosphatase alcaline.

Dans cette méthode, une concentration d'anticorps connue est placée dans un tube. On rajoute l'antigène lié (antigène marqué) de concentration connue et l'antigène libre (antigène non marqué et à doser), qui vont entrer en compétition de fixation sur l'anticorps. Après incubation, le précipité est récupéré par centrifugation et l'activité enzymatique présente est mesurée par addition d'un substrat donnant une réaction colorée. Plus la concentration d'antigène libre est grande, plus l'activité enzymatique enregistrée est faible. Cette activité est inversement proportionnelle à la concentration d'antigène libre.

Cette méthode existe aussi avec fixation préalable de l'anticorps sur un support solide (verre, plastique). Elle est connue dans ce cas, sous le nom de méthode Elisa (enzyme linked immunosorbent assay). Dans cette méthode, la séparation de l'antigène lié et de l'antigène libre se fait par un simple lavage.

La méthode Elisa dite « en sandwich » est la seule à avoir été appliquée pour le dosage des caséines $\mathrm{K}$ du lait et ne donne des résultats satisfaisants qu'avec des solutions de caséines purifiées de concentrations comprises entre $10^{-3} \mathrm{~g} / 1$ et $5 \times 10^{-2} \mathrm{~g} / 1$ (LEFIER et CoLLIN, 1982). Dans cette méthode, l'antigène doit posséder au moins deux déterminants antigéniques. L'antigène va se fixer à l'anticorps fixé au support et de concentration connue. Une quantité d'anticorps marqués et en excès est alors rajoutée au milieu. Après incubation, le milieu est lavé. Plus la concentration d'antigène est grande, plus la quantité d'anticorps fixés au support et occupés est élevée. Ainsi, la quantité d'anticorps marqués qui est retenue est plus grande ainsi que l'activité enzymatique enregistrée. Cette activité enzymatique est proportionnelle à la concentration en antigène.

Les réactifs (antigène marqué, anticorps marqué) peuvent se conserver des années sans perte de l'activité enzymatique. Il faut cependant s'assurer dans cette méthode que le milieu réactionnel ne renferme pas de substance inhibitrice de l'enzyme.

\section{Dosage immunonéphélémétrique}

Le principe de cette méthode (LeBReton et al., 1981) est la mesure de la lumière dispersée au contact des particules d'immunocomplexes formées en zone d'excès d'anticorps. Le cône de lumière dispersée est recueilli après 
focalisation sur un photodétecteur et le signal électrique créé, mesuré en volts, est proportionnel à la quantité d'immunocomplexe, elle-même proportionnelle à la quantité d'antigène rajoutée dans le milieu. L'appareil qui fait la mesure s'appelle un laser néphélémètre, qui fonctionne en continu. La méthode est rapide (un dosage toutes les 15 secondes). Elle s'est imposée comme méthode de routine pour la détection des immunoglobulines $\mathrm{G}$ du lait (LeBReton et al., 1981 ; JoISEL et al., 1981). Elle permet ainsi de détecter la présence de colostrum dont la teneur en immunoglobulines $\mathrm{G}$ est élevée, dans le lait. Le lait contenant du colostrum est, en effet, impropre à la consommation. Cette méthode possède une bonne sensibilité (de l'ordre du ng).

\section{J. Dosage des protéines par action de la carboxypeptidase A}

Cette méthode consiste à faire agir la carboxypeptidase $\mathrm{A}$, qui est une exopeptidase, sur un mélange de protéines. Cet enzyme libère les acides aminés à partir de l'extrémité $C$ terminale des protéines et son action est stoppée par des acides aminés tels que la proline, la lysine et l'arginine. Les acides aminés libres sont analysés directement à l'aide d'un analyseur d'acides aminés. Connaissant les séquences $C$ terminales des différentes protéines, le nombre de moles d'acides aminés libérés et spécifiques à chaque protéine, est proportionnel à la quantité de protéines présentes dans la solution. Cette méthode a été utilisée pour quantifier les différentes caséines (RIBADEAU-DUMAS, 1968). La précision de la méthode est limitée par la sensibilité de l'analyseur d'acides aminés. L'utilisation des analyseurs actuels permet une analyse rapide (une analyse par heure) et sensible (environ 1 nmole). Cette méthode pourrait être utilisée par le service de répression des fraudes pour détecter la présence de lait de vache dans le lait de chèvre. En effet, les séquences $\mathrm{C}$ terminales de protéines du lait de chèvre sont différentes de celles du lait de vache.

\section{Conclusion}

En conclusion de cette revue, il nous a semblé utile, par souci de clarté, de résumer sous forme de tableau les valeurs obtenues par différents auteurs lors du dosage des protéines du lait de vache. Ces valeurs sont classées en fonction de la nature des protéines à doser : protéines totales, caséine entière, protéines du sérum, différentes caséines et autres protéines du lait. Pour chaque référence citée, la race de l'animal et la méthode de dosage utilisée ont été précisées.

Les valeurs indiquées dans ce tableau font apparaître de grandes variations lors du dosage des protéines avec les différentes méthodes. Il semble cependant que la variabilité des résultats soit davantage imputable aux facteurs naturels de variation de la teneur en protéines du lait (stade de lactation, saison, alimentation, état sanitaire...) qu'à la méthode de dosage utilisée.

D'une manière générale, les méthodes de dosage rapide (principalement les méthodes de routine) ne permettent pas de doser les différentes protéines 
alors que celles qui le permettent (électrophorèse, chromatographie, techniques immunologiques) sont longues. Cependant, le développement des méthodes chromatographiques rapides (FPLC, HPLC) ouvrent de nouvelles perspectives par un abaissement important du temps d'analyse.

TENEURS DES DIFFERENTES FRACTIONS PROTEIQUES DU LAIT.

PROTEINES TOTALES $(g / 1)$

\begin{tabular}{|c|c|c|c|}
\hline Teneur & Réfé & śrence & \\
\hline 31,3 & Rolleri & et al & (1956) \\
\hline 34,6 & Rolleri & et al & (1956) \\
\hline & Rolleri & et al & (1956) \\
\hline 33,8 & Rolleri & et al & (1956) \\
\hline 31,5 & Ralleri & et al & (1956) \\
\hline 36,9 & Nakai & et al & (1964) \\
\hline 35,7 & Ashworth & & (1966) \\
\hline 34,1 & Wang et & Stone & (1967) \\
\hline 34,6 & Wang et & Stone & (1967) \\
\hline 33,9 & Mc Gann & et al & (1972) \\
\hline 36 & Haen? ein & et al & (1973) \\
\hline 41,6 & Haenlein & et al & (1973) \\
\hline 30,6 & Cerbul is & et Farre & $\mathrm{rel1}$ (1975) \\
\hline 35,5 & Cerbul is & et Farre & e11 (1975) \\
\hline 32,9 & Cerbul is & et Farre & (197) \\
\hline 40.7 & Cerbul is & et Farre & e11 (1975) \\
\hline 31,6 & Cerbul is & et Farre & (111 (1975) \\
\hline 38,3 & Cerbul is & et Farre & el1 (1975) \\
\hline 34,2 & Lin et $R$ & kandolph & (1978) \\
\hline 33,8 & Lin et $R$ & landolph & (1978) \\
\hline & Davies e & t Law & (1980) \\
\hline
\end{tabular}

\begin{tabular}{|c|c|}
\hline Race & éthode de dosage \\
\hline Brune Suisse & Kjeldahl \\
\hline Guernesey & Kjeldahl \\
\hline Holstein & Kjeldaht \\
\hline Jersey & Kjeldahi \\
\hline Ayrshire & Kjeldahi \\
\hline Guernesey & $\begin{array}{l}\text { Spectrometrie ultraviolet } \\
\text { Fixation de colorant }\end{array}$ \\
\hline & Kjeldahi \\
\hline & $\begin{array}{l}\text { Dumas } \\
\text { Fixation de colorant (Pro-Milk MK II) }\end{array}$ \\
\hline Holstein & Fixation de colorant \\
\hline Guernesey & Fixation de colorant \\
\hline Holstein & Kjeldahi \\
\hline Guernesey & Kjeldahi \\
\hline Ayrshire & Kjeldahl \\
\hline Jersey & Kjeldahl \\
\hline Milking Shorthorn & Kjeldahi \\
\hline Brune Suisse & Kjeldaht \\
\hline & $\begin{array}{l}\text { Kjeldahl } \\
\text { Kjeldahl }\end{array}$ \\
\hline Ayrshire-Frisone & Kjeldahl \\
\hline
\end{tabular}

CASEINES TOTALES $(g / 1)$

$\begin{array}{llll}27,8 & \text { Rolleri } & \text { et al } & (1956) \\ 28,8 & \text { Rolleri } & \text { et al } & (1956) \\ 23,3 & \text { Rolleri } \frac{\text { et al }}{\text { et }} & (1956) \\ 24,6 & \text { Rolleri } & \text { et al } & (1956) \\ 27,2 & \text { Rolleri } & \text { et ai } & (1956) \\ 20,1 & \text { Nakai } & \text { et al } & (1964) \\ 25,8 & \text { Mc Gann } & \text { et al } & (1972) \\ 27,9 & \text { Haenlein } & \text { et al } & (1973) \\ 31,9 & \text { Haenlein et al } & (1973) \\ 31,4 & \text { Cerbulis et Farrel1 } & (1975) \\ 25,6 & \text { Cerbulis et Farrel1 } & (1975) \\ 33,8 & \text { Cerbulis et Farre11 } & (1975) \\ 27,2 & \text { Cerbulis et farrel1 } & (1975) \\ 25,2 & \text { Cerbulis et Farrel1 } & (1975) \\ 28,7 & \text { Cerbulis et Farrel1 } & (1975) \\ 25,9 & \text { Davies et Law } & (1977 \text { b) } \\ 26,9 & \text { Davies et Law } & (1980) \\ 24,7 & \text { Mc Lean et al } & (1984) \\ 31,7 & \text { Mc Lean et al } & (1984)\end{array}$

$\begin{array}{ll}\text { Brune Suisse } & \text { Kjeldahl } \\ \text { Guernesey } & \text { Kjeldahi } \\ \text { Holstein } & \text { Kjeldahl } \\ \text { Ayrshire } & \text { Kjeldahl } \\ \text { Jersey } & \text { Kjeldah1 } \\ & \text { Spectrométrie ultraviolet } \\ & \text { Fixation de colorant (Pro-Milk MK II) } \\ \text { Holstein } & \text { Fixation de colorant } \\ \text { Guernesey } & \text { Fixation de colorant } \\ \text { Brune Suisse } & \text { Kjeldahl } \\ \text { Milking Shorthorn } & \text { Kjeldahl } \\ \text { Jersey } & \text { Kjeldahi } \\ \text { Ayrshire } & \text { Kjeldahi } \\ \text { Holstein } & \text { Kjeldahl } \\ \text { Guernesey } & \text { Kjeldahl } \\ \text { Ayrshire } & \text { Kjeldahl } \\ \text { Ayrshire-Frisone } & \text { Kjeldahi } \\ \text { Frisone } & \text { Fixation de colorant (Pro-Milk MK II) } \\ \text { Jersey } & \text { Fixation de colorant (Pro-Milk MK II) } \\ \end{array}$

PROTEINES TOTALES DU LACTOSERUM $(g / 1)$

\begin{tabular}{|c|c|c|c|}
\hline 5,3 & Rolleri & et al & (1956) \\
\hline 5,8 & Rolleri & et al & (1956) \\
\hline 5,6 & Rolleri & et al & 1956) \\
\hline 5,1 & Rolleri & $\overline{\text { et } a 1}$ & 956 \\
\hline 6,6 & Rolleri & $\overline{\text { et al }}$ & 56 \\
\hline 12,5 & Nakai & $\overline{\text { et } a 1}$ & 64 \\
\hline 7,9 & Mc Gann & $\overline{\text { et al }}$ & 972 \\
\hline 9,0 & Haenlein & et al & 973) \\
\hline 8,2 & Haenlein & et al & 973) \\
\hline 5,7 & Cerbulis & et Farrell & (1975) \\
\hline & Cerbul is & et Farrell & (1975) \\
\hline & Cerbulis & et Farrell & 975) \\
\hline & Cerbulis & et Farrell & 75 ) \\
\hline & Cerbul is & et Farrell & 975) \\
\hline & Cerbul is & et Farrell & \\
\hline & Li & 100 & \\
\hline i & $\begin{array}{l}\text { Lin et } \\
\text { Davies }\end{array}$ & $\begin{array}{l}\text { andolph } \\
\text { t Law }\end{array}$ & $\begin{array}{l}(1978) \\
(1980)\end{array}$ \\
\hline
\end{tabular}

\begin{tabular}{|c|c|}
\hline Brune Suisse & Kjeldahl \\
\hline Guernesey & Kjeldahl \\
\hline Holstein & Kjeldahl \\
\hline Ayrshire & Kjeldahl \\
\hline Jersey & $\begin{array}{l}\text { Kjeldah1 } \\
\text { Spectrom }\end{array}$ \\
\hline Guernesey & $\begin{array}{l}\text { Fixation } \\
\text { Kjeldahl }\end{array}$ \\
\hline Holstein & Kjeldahl \\
\hline Ayrshire & Kjeldah \\
\hline Brune Suisse & Kjeldah \\
\hline Milking Shorthorn & Kjeldah \\
\hline Jersey & Kjeldal \\
\hline Holstein & Kjeldah \\
\hline Guernesey & $\begin{array}{l}\text { Kjeldaht } \\
\text { Kjeldahl }\end{array}$ \\
\hline A & \\
\hline
\end{tabular}

$\begin{array}{lll}9,96 & \text { Davies et Law } & (1977 \text { b) } \\ 10,25 & \text { Davies et Law } & (1980) \\ 10,1 & \text { Mc Lean et al } & (1984)\end{array}$

CASEINE $a_{S 1}(g / 1)$

8,3 Mc Lean etal (1984)

$\begin{array}{ll}\text { Ayrshire } & \text { DEAE Cellulose } \\ \text { Ayrshire-Frisone } & \text { DEAE Cellulose } \\ \text { Jersey } & \text { Electrophorèse } \\ \text { Frisone } & \text { Electruphorèse }\end{array}$


TENEURS DES DIFFERENTES FRACTIONS PROTEIQUES DU LAIT. PROTEINES TOTALES $(g / 1)$

Teneur Référence

2,72 Davies et Law

2,74 Davies et Law

2,9 Mc Lean et al

4,1 Mc Lean et al

$\begin{array}{ll}13,3 & \text { Haenlein et al } \\ 15,6 & \text { Haenlein et al }\end{array}$

8,4. Rolleri et a

8,2 Rolleri et a

6,0 Rolleri et a

8,5 Rolleri et al

7,6 Rolleri et al

10,6 Haenlein et a

12,0 Haenlein et al

9,46 Davies et Law

9,6 Davies et Law

8,8 Mc Lean et al

10,8 Mc Lean et al

1,6 Haenlein et al

1,8 Haenlein et al

3,2 Davies et Law

3,4 Davies et Law

2,7 Beeby

$\begin{array}{ll}2,7 & \text { Mc Lean et al } \\ 3,9 & \text { Mc Lean et al }\end{array}$

1,1 Rolleri et al

1,4 Rolleri $\frac{\text { et al }}{\text { et }}$

2,0 Rolleri etal

0,8 Rolleri etal

1,3 Rolleri et al

0,5 Davics et Law

0,8 Davies et Law

2,1 Mc Lean et al

2,7 Mc Lean et a1

38 Davies et Law

38, 4 Davies et Law

38, 1 Davies et Law

33,6 Mc Lean et al

31,9 Mc Lean et al

31,8 Mc Lean et al

33,6 Mc Lean etal

11 Davies et Law

10,5 Davies et Law

10,2 Davies et Law

11,7 Mc Lean et a

12,8 Mc Lean et a

11,7 Mc Lean et al

12.9 Mc Lean et a

$49 \quad$ Tessier

46,8 Ribadeau-Dumas

48,9 Haenlein et al

47,8 Haenlein et al

51,2 Randolph et al

49 Davies et Law

48,9 Davies et Law

49,6 Barry et Donnelly

48,7 Barry et Donnelly

48,3 Davies et Law

44,7 Mc Lean et al

45,3 Mc Lean et al

45,3 Mc Lean et al

44,7 Mc Lean et al
Race

Méthode de dosage

CASEINE a s2 $(g / 1)$

$(1977$ b)
$(1980)$
$(1984)$
$(1984)$

$(1973)$

(1956)

(1956)

(1956)

(1956)

(1973)

(1973)

(1977 b)

(1980)

(1984)

(1984)

$(1973)$
$(1973)$
$(1977 b)$
$(1980)$
$(1980)$
$(1984)$
$(1984)$

Ayrshire

Jersey

DEAE Cellulose

Electrophorèse

Electrophorèse

CASEINE a $(g / 1)$

Holstein

Electrophorèse

Guernesey Electrophorèse

CASEINE $\beta(\mathrm{g} / 1)$

Brown swiss

Guernesey

Holstein

Ayrshire

Holstein

Holstein

Guernesey

Ayrshire

DEAE Cellulose

Ayrshire-Frisone DEAE-CEIlulose

Frisone Electrophorèse

Jersey Electrophorèse

CASEINE $\kappa(g / 7)$

$\begin{array}{ll}\text { Holstein } & \text { Electrophorèse } \\ \text { Guernesey } & \text { Electrophorèse } \\ \text { Ayrshire } & \text { DEAE Cellulose } \\ \text { Ayrshire-Frisone } & \text { DEAE Cellulose } \\ & \text { Fluorescamine } \\ \text { Frisone } & \text { Electrophorèse } \\ \text { Jersey } & \text { Electrophorèse }\end{array}$

CASEINE $\gamma(g / 7)$

(1956)

(1956)

(1956)

(1956)

(1956)

(1977 b)

(1980)

(1984)

(1984)

Brune Suisse

Guernesey

Holstein

Ayrshire

Jersey

Jersey

Ayrshire

Frisone

Electrophorèse

Electrophorèse

Electrophorèse

Electrophorèse

Electrophorèse

Electrophorèse

CASEINE $a_{s 1}$ (\% pour $100 \%$ de caséine)

$(1977$ a)
$(1977$ b)
$(1980)$
$(1982)$
$(1982)$
$(1984)$
$(1984)$

Ayrshire
Ayrshire
Ayrshire-Frisone
Frisone
Jersey
Jersey
Frisone

DEAE Cellulose DEAE Cellulose DEAE Cellulose Electrophorèse Electrophorèse Electrophorèse Electrophorèse

CASEINE $a_{S 2}$ ( $\%$ pour $100 \%$ de caséine)

$\begin{array}{lll}(1977 \text { a) } & \text { Ayrshire } & \text { DEAE Cellulose } \\ (1977 \text { b) } & \text { Ayrshire } & \text { DEAE Cellulose } \\ (1980) & \text { Ayrshire-Frisone } & \text { DEAE Cellulose } \\ (1982) & \text { Frisone } & \text { Electrophorèse } \\ (1982) & \text { Jersey } & \text { Electrophorèse } \\ (1984) & \text { Frisone } & \text { Electrophorèse } \\ (1984) & \text { Jersey } & \text { Electrophorèse }\end{array}$

CASEINE $a_{5}$ (\% pour $100 \%$ de caséine)

$(1963)$
$(1968)$
$(1973)$
$(1973)$
$(1974)$
$(1977$ a
$(1977$ b
$(1979)$
$(1980)$
$(1980)$
$(1982)$
$(1982)$
$(1984)$
$(1984)$

Turbidimétrie Carboxypeptidase Electrophorèse Electrophorèse Electrophorèse DEAE Cellulose DEAE Cellulose Hydroxyapatite Hydroxyapatite DEAE Cellulose
Electrophorèse Electrophorèse Electrophorèse Electrophorèse 
TENEURS DES DIFFERENTES FRACTIONS PROTEIQUES DU LAIT.

PROTEINES TOTALES $(\mathrm{g} / 1)$

Teneur Référence Race Méthode de dosage

CASEINE $\beta$ ( $\%$ pour $100 \%$ de caséine)

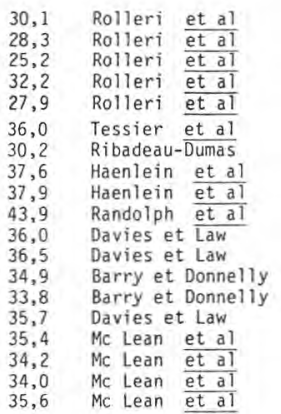

$(1956)$
$(1956)$
$(1956)$
$(1956)$
$(1956)$
$(1963)$
$(1968)$
$(1973)$
$(1973)$
$(1974)$
$(1977$ a)
$(1977$ b)
$(1979)$
$(1980)$
$(1980)$
$(1982)$
$(1982)$
$(1984)$
$(1984)$

Brune Suisse
Guernesey
Holstein
Ayrshire
Jersey
Guernesey
Holstein
Ayrshire
Ayrshire
Frisone
Frisone
Ayrshire-Frisone
Frisone
Jersey
Jersey
Frisone

Electrophorèse Electrophorèse Electrophorèse Electrophorèse Turbidimétrie Carboxypeptidase A

Electrophorèse

Electrophorèse Electrophorèse DEAE Cellulose DEAE Cellulose Hydroxyapatite Hydroxyapatite DEAE Cellulose DEAE Cel1ulose
Electrophorèse Electrophorèse Electrophorèse Frisone Electrophorèse

CASEINE K (\% pour $100 \%$ de caséine)

$\begin{aligned} 10,0 & \text { Tessier et al } \\ 10,6 & \text { Ribadeau-Dumas } \\ 5,6 & \text { Haenlein et al } \\ 5,7 & \text { Haenlein et a T } \\ 3,3 & \text { Randolph et al } \\ 13,0 & \text { Davies et Law } \\ 12,5 & \text { Davies et Law } \\ 10,2 & \text { Barry et Donne 11y } \\ 9,5 & \text { Barry et Donne11y } \\ 12,8 & \text { Davies et Law } \\ 10,8 & \text { Mc Lean et al } \\ 12,4 & \text { Mc Lean et al } \\ 10,9 & \text { Mc Lean et a1 } \\ 12,3 & \text { Mc Lean et a1 }\end{aligned}$

$(1963)$
$(1968)$
$(1973)$
$(1973)$
$(1974)$
$(1977$ a)
$(1977$ b)
$(1979)$
$(1980)$
$(1980)$
$(1982)$
$(1982)$
$(1984)$
$(1984)$

Dosage des acides sialiques Carboxypentidase A

Guernesey Electrophorese

Holstein Electrophorèse

Electrophorèse $\begin{array}{ll} & \text { Electrophorese } \\ \text { Ayrshire } & \text { DEAE Cellulose }\end{array}$ Ayrshire DEAE Cellulose Frisone Hydroxyapatite Frisone Hydroxyapatite $\begin{array}{ll}\text { Frisone } & \text { Hydroxyapatite } \\ \text { Ayrshire-Frisone } & \text { DEAE Cellulose }\end{array}$ Frisone Electrophorèse Jersey Electrophorèse Frisone Electrophorèse $\begin{array}{ll}\text { Frisone } & \text { Electrophorèse }\end{array}$

CASEINE $\gamma$ ( $\%$ pour $100 \%$ de caséine)

$\begin{array}{ll}4,1 & \text { Rolleri et al } \\ 5,2 & \text { Rolleri etal } \\ 8,5 & \text { Rolleri etal } \\ 3,1 & \text { Rolleri etal } \\ 4,8 & \text { Rolleri et al } \\ 2,0 & \text { Davies et Law } \\ 2,1 & \text { Davies et Law } \\ 3,4 & \text { Barry et Donnelly } \\ 4,9 & \text { Barry et Donnelly } \\ 3,2 & \text { Davies et Law } \\ 8,6 & \text { Mc Lean et a1 } \\ 8,5 & \text { Mc Lean et al } \\ 8,5 & \text { Mc Lean et al } \\ 8,5 & \text { Mc Lean et al }\end{array}$

$\begin{array}{lll}(1956) & \text { Brune Suisse } & \text { Electrophorèse } \\ (1956) & \text { Guernesey } & \text { Electrophprèse } \\ (1956) & \text { Holstein } & \text { Electrophorèse } \\ (1956) & \text { Ayrshire } & \text { Electrophorèse } \\ (1956) & \text { Jersey } & \text { Electrophorèse } \\ (1977 \text { a) } & \text { Ayrshire } & \text { DEAE Cellulose } \\ (1977 \text { b) } & \text { Ayrshire } & \text { DEAE Cellulose } \\ (1979) & \text { Frisone } & \text { Hydroxyapatite } \\ (1980) & \text { Frisone } & \text { Hydroxyapatite } \\ (1980) & \text { Ayrshire-Frisone } & \text { DEAE Cellulose } \\ (1982) & \text { Jersey } & \text { Electrophorèse } \\ (1982) & \text { Frisone } & \text { Electrophorèse } \\ (1984) & \text { Jersey } & \text { Electrophorèse } \\ (1984) & \text { Frisone } & \text { Electrophorèse }\end{array}$

B LACTOGLOBULINE $(g / 1)$

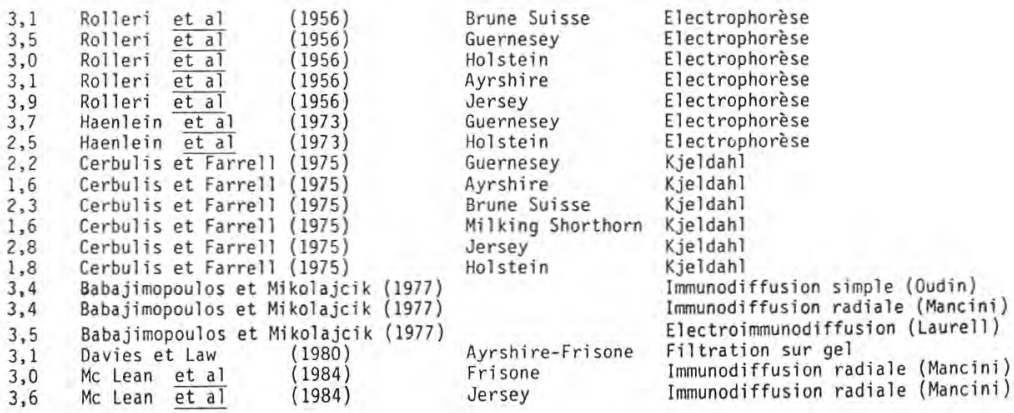


TENEURS DES DIFFERENTES FRACTIONS PROTEIQUES DU LAIT. PROTEINES TOTALES $(g / 1)$

\section{Teneur Référence}

$\begin{array}{ll}1,1 & \text { Rolleri et al } \\ 1,5 & \text { Rolleri } \frac{\text { et al }}{\text { et al }} \\ 1,1 & \text { Rolleri } \frac{\text { et }}{\text { et al }} \\ 1,3 & \text { Rolleri } \frac{\text { et al }}{1,1} \\ 2,8 & \text { Rolleri } \\ 2,7 & \text { Haenlein ein et al } \\ 1,3 & \text { Beck et Tucker } \\ 1,2 & \text { Davies et Law } \\ 0,9 & \text { Mc Lean et al } \\ 1,1 & \text { Mc Lean etal }\end{array}$

Race

a LACTALBUMinE $(g / 1)$
Méthode de dosage

\begin{tabular}{|c|c|}
\hline $\begin{array}{l}0,4 \\
0,4 \\
0,4 \\
0,4 \\
0,3 \\
1,5 \\
1,4 \\
0,2 \\
0,2 \\
0,2 \\
0,4\end{array}$ & $\begin{array}{l}\text { Rolleri etal } \\
\text { Rolleri etal } \\
\text { Rolleri etal } \\
\text { Rolleri etal } \\
\text { Rolleri etal } \\
\text { Haenlein etal } \\
\text { Haenlein etal } \\
\text { Babajimopoulos e } \\
\text { Babajimopoulos e } \\
\text { Babajimopoulos } \\
\text { Davies et Law }\end{array}$ \\
\hline $\begin{array}{l}0,7 \\
0,8 \\
0,9 \\
0,8 \\
0,6 \\
1,4 \\
1,6\end{array}$ & $\begin{array}{l}\text { Rolleri et al } \\
\text { Rolleri } \frac{\text { et al }}{\text { et al }} \\
\text { Rolleri } \frac{\text { et et al }}{\text { Rolleri }} \\
\text { Rolleri etal } \\
\text { Haenlein etal } \\
\text { Haenlein etal }\end{array}$ \\
\hline
\end{tabular}

0,9 Davies et Law

(1980)

18,9.10-3 Beck et Tucker

(1980)

$(1956)$
$(1956)$
$(1956)$
$(1956)$
$(1956)$
$(1973)$
$(1973)$

Brune Suisse
Jersey
Guernesey
Holstein
Ayrshire
Holstein
Guernesey
Holstein-Frisone
Ayrshire-Frisone
Frisone
Jersey

Jersey

SERUM ALBUMINE $(\mathrm{g} / 1)$

Brune Suisse
Guernesey
Holstein
Jersey
Ayrshire
Holstein
Guernesey

\author{
Electrophorèse \\ Electrophorèse \\ Electrophorèse \\ Electrophorèse \\ Electrophorèse \\ Electrophorèse \\ Electrophorèse \\ Radioimmunologie \\ Filtration sur gel \\ Immunodiffusion radiale (Mancini) \\ Immunodiffusion radiale (Mancini)
}

Electrophorèse

Electrophorèse

Electrophorèse

Electrophorèse

Electrophorèse

Electrophorèse

Electrophorèse

Immunodiffusion simple (Oudin)

Immunodiffusion radiale (Mancini)

Electroimmunodiffusion (Laurell)

Ayrshire-Frisone

Filtration sur ge

\section{IMWUNOGLOBULINES $6(\mathrm{~g} / \mathrm{l})$}

Brune Suisse

Guernesey

Holstein

Jersey

Ayrshire

Holstein

Guernesey

Electrophorèse

Electrophorèse

Electrophorèse

Electrophorèse

Electrophorèse

Electrophorese

Electrophorèse

LACTOFERRINE $(g / 1)$

Ayrshire-Frisone Filtration sur gel

PROLACTINE $(g / l)$

Hostein-Frisone Radioimmunologie 


\section{Références bibliographiques}

adda J., Blanc-Patin E., Jeunet R., Grappin R., Mocquot G., Ricordeau G., 1967. Essais d'utilisation d'un spectrophotomètre infrarouge (infrared milk analyser) permettant de déterminer la teneur du lait en matière grasse, matière azotée et lactose. Bull. Tech. Inf., 225, 947-958.

adda J., Blanc-Patin E., Jeunet R., Grappin R., Mocouot G., Pousardieu B., Ricordeau G., 1968. Essais d'utilisation de l'infrared milk analyser. Lait, 48, 145-153 et 293-302.

Addeo F., Mercier J.C., Ribadeau Dumas B., 1977. The caseins of buffalo milk. J. Dairy Res., 44, 455-468.

AIMUTIS W.R., EIGEL W.N., 1982. Identification of $\lambda$-casein $\alpha_{s}$ plasmin derived fragments of bovine $\alpha_{\text {st }}$-casein. J. Dairy Sci., 65, 175-181.

Alais C., Ribadeau Dumas B., Saint-Lebe L., 1961. Etude de la réaction des protéines du lait avec le "noir amido". Application au dosage rapide des matières azotées du lait. Lait, 41, 241-273.

AlaIs C., 1984. Science du lait, principes et techniques Iaitières. $4^{\mathrm{e}}$ édition, Sepaic, Paris.

ANDREWS A.T., 1979. The formation and structure of some proteose peptone components. J. Dairy Res., 46, 215-218.

AsChAFFEnBURg R., DREWRY J., 1959. New procedure for the routine determination of the various non-casein proteins of milk. $15^{\circ} \mathrm{Cong}$. Int. Lait., 3, 1631.

AsHWoRTH V.S., 1966. Determination of protein in dairy products by Dye-Binding. $J$. Dairy Sci., 49, 133-137.

Babajimopoulos M., Mikolajcik E.M., 1977. Quantification of selected serum protein of milk by immunological procedures. J. Dairy Sci., 60, 721-725.

Barrefors P., Ekstrand B., Fagerstrass L., Larsson RazntKiewicz M., SchaAR J., Steffiner P., 1985. Fast protein liquid chromatography (FPLC) of bovine caseins. Milchwissenschaft, $40,257-260$.

BARRY J.G., DoNnELLY W.J., 1979. A method for the quantitative analysis of bovine casein. Biochem. Soc. Trans., 7, 529-531.

Barry J.G., Donnelly W.J., 1980. Casein compositional studies. 1. The composition of casein from Friesian herd milks. J. Dairy Res., 47, 71-82.

Basch J.J., Douglas F.W., Procino L.G., Holsinger V.H., Farrell H.M., 1985. Quantitation of caseins and whey proteins of processed milks and comparison with HarlandAshword procedure. J. Dairy Sci., 68, 23-31.

BECK N.F.G., TUCKER H.A., 1977. Relationships between radioimmunoassays of $\alpha$-lactalbumin and prolactin in bovine skim milk. J. Dairy Sci., 60, 542-545.

BEEBY R., 1980. The use of fluorescamine at $\mathrm{pH} 6.0$ to follow the action of chymosin on K-casein and to estimate this protein in milk. N Z. J. Dairy Sci. Technol., 15, 99-108.

BEECHER G.R., 1970. Ammonia determination : reagent modification and interfering compounds. Anal. Biochem., 36, 243-246.

Beitz D.C., Phillips M.E., EkLund S.H., 1977. A nephelometric procedure for determination of fat and protein in milk. J. Dairy Sci, 60, 701-705.

BIETZ J.A., 1974. Micro Kjeldahl analysis by an improved automated ammonia determination following manual digestion. Anal. Chem., 46, 1617-1618.

BigGs D.A., 1967. Milk analysis with the infrared milk analyzer. J. Dairy Sci., 50, 799-803.

BIGgS D.A., 1972 a. Precision and accuracy of infrared milk analysis, J. Assoc. Off. Anat. Chem., 55, 488-497.

BigGs D.A., 1972 b. Infrared milk analyser. J. Dairy Sci., 55, 650-651.

BIGGS D.A., 1978. Instrumental infrared estimation of fat, protein and lactose in milk : collaborative study. J. Assoc. Off. Anal. Chem., 61, 1015-1034.

BIGGS D.A., 1979. Infrared estimation of fat, protein and lactose in milk : evaluation of multispec instrument I. Assoc. Off. Anal. Chem., 62, 1202-1207.

Blanc B., 1982. Les protéines du lait à activité enzymatique et hormonale. Lait, 62, 350-395.

Bortree A.L., Carroll E.J., Schalm O.W., 1962. Whey protein patterns of milk from cows with experimentally produced mastitis. I. Dairy Sci., 45, 1465-1471. 
Bosset J.O., Blanc B., Plattner E., 1976. Le dosage des protéines du lait et de ses principaux dérivés : méthodes et appareillages tirés de la littérature parue entre 1964 et 1974. Trav. Chim. Alim. Hyg., 67, 226-261.

Brignon G., Chtourou A., Ribadeau Dumas B., 1986. Contamination of human whole casein by whey proteins : quantitative aspects. Lait (sous presse).

Brown P.B., ClaRk R.M., LaBarre D.J., Ross S.R., 1983. A comparison of methods for protein analysis of human milk. Fed. Proc., 42, 1330.

Cerbulis J., Farrell H.M., 1975. Composition of milks of dairy cattle. I. Protein, lactose and fat contents and distribution of protein fraction. J. Dairy Sci., 58, 817-827.

Church F.C., Swaisgood H.E., Porter D.H., Catignani G.L., 1983. Spectrophotometric assay using ophtaldialdehyde for determination of proteolysis in milk and isolated milk proteins. J. Dairy Sci., 66, 1219-1227.

DAVIES D.T., 1974. The quantitative partition of the albumin fraction of milk serum proteins by gel chromatography. J. Dairy Res., 41, 217-228.

DAVIES D.T., LAW A.J.R., 1977 a. An improved method for the quantitative fractionation of casein mixtures using ion exchange chromatography. J. Dairy Res,, 44, 213-221.

Davies D.T., Law A.J.R., 1977 b. The composition of whole casein from the milk of Ayshire cows. J. Dairy Res., 44, 447-454.

Davies D.T., LAW A.J.R., 1980. The content and composition of protein in creamery milks in south-west Scotland. J. Dairy Res., 47, 83-90.

Dellamonica E.S., Holden T.F., Calnhoun M.J., Aceto N.C., 1965. Effect of season on the whey protein nitrogen distribution of pooled milk. J. Dairy Sci., 48, 1585-1590.

DESCHREIDER A.R., MEAUX R., 1973. Utilisation d'une électrode ionique pour le dosage de l'azote par la méthode de Kjeldahl. Analusis, 2, 442-445.

Dill C.W., Mc Gml R., Lane G.T., Bryant J.N., Thompson Y., 1972. Distribution changes in bovine skim milk proteins during forced milk release. J. Dairy Sci., 55, 200-203.

DoNNELLY W.J., 1977. Chromatography of milk proteins on hydroxyapatite. I. Dairy Res., $44,621-625$.

Driou A., Godbillon G., Linden G., 1985. Dosage de la poudre de lait écrémé par méthode immunologique dans les produits alimentaires pour animaux. Sci. Aliments, 5, 73-88.

Dydenkov A., 1966. Modification of Kofranyi method for determination of quantity of protein substances in milk and sweetened condensed milk. 17st Int. Dairy Cong. B, 183-185.

Egli H.R., MEyHack U., 1984. Measurements of the principal constituents of solid and liquid milk products by means of near infrared analysis. Challenges to contemporary dairy analytical techniques. The Royal Society of Chemistry, Burlington House, London, 49, $103-116$.

Folin O., Ciocalteu V., 1927. On Tyrosine and Tryptophane determinations in proteins. J. Biol. Chem., 73, 627-650.

Forsum E., 1976. Determination of $\alpha$-lactalbumin in human milk. J. Dairy Sci., 59, 14-18.

Fox K.K., Holsinger V.H., Pallansch M., 1963. Fluorimetry as a method of determining protein content of milk. J. Dairy Sci., 46, 302-309.

Goulden J.D.S., 1964. Analysis of milk by infrared absorption. J. Dairy Res., 31, 273-284.

GRAPPin R., JeUnet R, 1971. Essais de l'appareil « pro-milk automatique » destiné au dosage en série de la matière azotée du lait. Lait, 51, 35-49.

GRAPPIN R., JEunET R., 1976 a. Calibrage des méthodes de dosage de routine des protéines du lait. Rev. Lait. Fr., 347, 663-667.

Grappin R., Jeunet R., 1976 b. Essais de l'appareil Milko Scan 300 utilisé pour le dosage en série de la matière grasse et des protéines du lait. Lait, 56, 498-520.

Grappin R., 1976 c. Guide pour l'évaluation des méthodes analytiques de routine. Lait, $56,608-621$.

GRAPPIN R., JeUnET R., 1979. Méthodes de routine pour le dosage de la matière grasse et des protéines du lait de chèvre, Lait, 59, 345-360. 
GraPPIN R., PACKaRd V.S., GINN R.E., 1980. Repeatability and accuracy of Dye-binding and infrared methods for analyzing protein and other milk components. I. Food Prot., $43,374-375$ and 380 .

Grosclaude F., Mahé M.F., Mercier J.C., Ribadeau Dumas B., 1972. Caractérisation des variants génétiques des caséines $\alpha_{\mathrm{S} 1}$ et $\beta$-bovines. Eur. J. Biochem., 26, 328-337.

GUIDRY A.J., PEARSON R.E., 1979. Improved methodology for quantitative determination of serum and milk proteins by single radial immunodiffusion. J. Dairy Sci., 62, 1252-1257.

Haenlein G.F.W., SchultZ L.H., ZiKakis J.P., 1973. Composition of proteins in milk with varying leucocyte contents. J. Dairy Sci., 56, 1017-1024.

Harland D.A., CoUlter S.T., Jenness R., 1955. Natural variations of milk serum proteins as a limitation of their use in evaluating the heat treatment of milk. J. Dairy Sci., $38,858-869$.

HUdSON G.J., LuCAS A., 1983. Nitrogen content of human milk : limitations of spectrophotometry for the determination of protein in milk. J. Dairy Res., 50, 269-274.

HUMPHREY R.S., NEWSOME L.J., 1984. High performance ion-exchange chromatography of the major bovine milk proteins. N.Z.J. Dairy Sci. Technol., 19, 197-204.

Iwaida M., Kawaguchi Y., Tsugo T., 1967. Ultraviolet spectrophotometric determination of protein content in milk. J. Dairy Sci., 50, 1322-1327.

Joisel F,, Lannuzel B., Lebreton J.P., Boutleux S., Sauger F., 1981. Dosage immunonéphélométrique des immunoglobulines $\mathrm{G}$ du lait de vache. II. Application à la détection de la présence de colostrum dans les laits de mélange. Lait, 61, 568-589.

JoHnston K.A., 1982. Evaluation of the Multispec instrument for infrared estimation of milk fat, protein and lactose in raw milk.N.Z. J. Dairy Sci. Technol., 17, 141-146.

Kaminogawa S., Yamauchi K., 1972. Acid protease of bovine milk. Agric. Biol. Chem., 36, 2351-2356.

Kramme D.G., Griffen R.H., Hartford C.G., Corrado J.A., 1973. Automated Kjeldahl Nitrogen determination. A comprehensive method for aqueous dispersible samples. Anal. Chem., 45, 405-408.

Kroger M., Katz E.E., Weaver J.C., 1978. Determining protein content of ice cream and frozen desserts. J. Dairy Sci., 61, 274-277.

KWAI HANG K.F.N.G., Hayes J.F., 1982. Effects of potassium dichromate and sample storage time on fat and protein by milko-Scan and on protein and casein by a modified MKII method. J. Dairy Sci., 65, 1895-1899.

KWAI HANG K.N.F.G., KRoEKER E.M., 1984, Rapid separation and quantification of major caseins and whey proteins of bovine milk by polyacrylamide gel electrophoresis. J. Dairy Sci., d7, 3052-3056.

LAKIN A.L., 1974. Etude comparée des quantités de colorants fixées par les protéines du lait dans les conditions habituelles des procédés de fixation des colorants. XIX Cong. Int. Lait., Vol. $1 \mathrm{~F}, 303-304$.

LAURELL C.B., 1966. Quantitative estimation of proteins by electrophoresis in agarose gel containing antibodies. Anal. Biochem., 15, 45-52.

Lebreton J.P., Joisel F., Boutleux S., Lannuzel B., Sauger F., 1981. Dosage immunonéphélométrique des immunoglobulines $\mathrm{G}$ dans le lait de vache. I. Mise au point technique du dosage. Lait, 61, 465-480.

Lefier D., Collin J.C., 1982. Contribution au dosage des caséines K de vache par une méthode immunoenzymatique. Lait, 62, 541-548.

LiN R.H., RanDolPH H.E., 1978. Determination of nitrogen in milk by microdiffusion of Kjeldahl digests. J. Dairy Sci., 61, 870-873.

LonNerdal B., Forsum E., Hambraeus L., 1976. The protein content of human milk. I. A transversal study of Swedish normal material. Nutr. Rep. Int., 13, 126-134.

Lowry O.H., Rosebrough N.J., FARR A.R., RANdall R.J., 1951. Protein measurement with the Folin phenol reagent. J. Biol. Chem., 193, 265-275.

LUKE H.A., 1967. Collaborative testing of the dye-binding method for milk protein. J. Assoc. Off. Anal. Chem., 50, 560-564. 
Mc Gann T.C.A., Mathiassen A., O'Connell J.A., 1972. Applications of the Pro-Milk MK II part. III. Rapid estimation of casein in milk and protein in whey. Lab. Pract., 21, 628-650.

Mc Grath R., 1972. Protein measurement by Ninhydrin determination of amino acids released by alcaline hydrolysis. Anal. Biochem., 49, 95-102.

Mc Lean D.M., Graham E.R.B., Mc Kenzie H.A., 1982. Estimation of casein composition by electrophoresis. 21st Int. Dairy Cong., Moscow, 1 (2), 221.

Mc Lean D.M., Graham E.R.B., Ponzoni R.W., 1984. Effects of milk protein genetic variants on milk yield and composition. J. Dairy Res., 51, 531-546.

Mancini G., Carbonara A.O., Heremans J.F., 1965. Immunochemical quantitation of antigens by single Radial Immunodiffusion. Immunochem., 2, 235-254.

MARIER J.R., TESSIER H., Rose D., 1963. Sialic acid as an index of the K-casein content of bovine skim milk. J. Dairy Sci., 46, 373-379.

MASSEYEF R., 1978. L'immunoenzymologie. Rapports. Dosages enzymologiques. Principes et applications. Ann. Biol, Clin,, 36, 375-382.

Mercier J.C., Maubois J.L, Poznanski S., Ribadeau Dumas B., 1968. Fractionnement préparatif des caséines de vache et de brebis par chromatographie sur DEAE cellulose, en milieu urée et 2-mercaptoéthanol. Bull. Soc. Chim. Biol., 50, 521-530,

MichilaK W., CynalewSKa H., Oczkowicz H., 1978. Collaborative testing among laboratories routinely testing fat and protein in milk. J. Dairy Sci., 61, 1634-1636.

MORRIS G.F., CARSON R.B., SHEARER D.A., JopKIEWICZ W.T., 1968. Comparison of the automatic Dumas (Coleman model 29A Nitrogen Analyzer II) and Kjeldahl methods for the determination of total nitrogen in agricultural materials. J. Assoc. Off. Anal. Chem., $51,216-219$.

Nagasawa T., Kiyosawa I., Kuwahara K., Fukuwatari Y., Suzuki T., 1972. Gel electrophoresis patterns of human milk protein with duration and temperature of storage of the milk. J. Dairy Sci., 55, 289-293.

Nagasawa T., Kryosawa I., Fukuwatari Y., Kitayama T., Uechi M., Hyodo Y., 1973. $\alpha$-lactalbumin and serum albumin in human milk. J. Dairy Sci., 56, 177-180.

NAKaI S., Wilson H.K., HerReid E.O., 1964. Spectrophotometric determination of protein in milk. J. Dairy Sci., 47, 356-358.

NAKAI S., Chile H., 1970. Spectrophotemetric determination of protein and fat in milk simultaneously. J. Dairy Sci., 53, 276-278.

Noble R.C., Shand J.H., West I.G., 1979. The use of liquid scintillation counter in colorimetric analysis. Lab. Pract., 28, 393-396.

Noble R.C., Shand J.H., 1980. Quantification of protein, fat and lactose concentrations in milk samples using a liquid scintillation counter. Proc. Nutr. Soc., 39, 78A.

Noble R.C., Shand J.H., West I.G., 1981. Novel determination of protein, fat and lactose of milk by liquid scintillation counter. J. Dairy Sci., 64, 14-18.

PEARCE R.J., 1983. Analysis of whey proteins by high performance liquid chromatography. Aust. J. Dairy Technol., 38, 114-117.

PoRTER R.M., 1965. Fluorometric determination of protein in whole milk, skim milk serum. J. Dairy Sci., 48, 99-100.

RANDOLPH H.E., ERWIN R.E., RICHTER R.L., 1974. Influence of mastitis on properties of milk. VII. Distribution of milk proteins. J. Dairy Sci., 57, 15-18.

Ribadeau Dumas B., 1968. Simultaneous determination of $\alpha_{S_{1}}, \beta$ and K-caseins in whole casein by using carboxypeptidase A. Biochim. Biophys. Acta, 168, 274-281.

Ribadeau Dumas B., 1979. Progrès récents dans la biochimie des protéines du lait. Rev. Lait. Fr., 371, 1-15.

Rittenburg J.H., Ghaffar A., Smith C.J., Adams S., Allen J.C., 1984. The estimation of casein in milk by an enzyme linked immunosorbent assay. Challenges to contemporary dairy analytical techniques. The royal society of chemistry, Burlington House, London, $49,319-320$.

ROEPER J., 1974. Formol titration method of estimating true protein and casein in skim milk. N.Z.J. Dairy Sci. Technol., 9, 49-50. 
Rolleri G.B., Larson B.L., TouchberRy R.W., 1956. Protein production in the bovine breed and individual variations in the specific protein constituents of milk. J. Dairy Sci., $39,1683-1689$.

Rose D., Davies D.T., Yaguchi M., 1969. Quantitative determination of the major components of casein mixtures by column chromatography on DEAE-Cellulose. J. Dairy Sci., 52, 8-11.

Rowland S.J., 1938. The precipitation of the proteins in milk. J. Dairy Res., 9, 30-41.

Schanbacher F.L., Smith K.L., 1974. Electroimmunodiffusion on cellulose acetate : a rapid method for analysis of bovine lactoferrin in chromatography effluents. Anal Biochem., $59,235-247$.

SchmidT D.G., 1982. Association of caseins and casein micelle structure.Chap. 2. In Developments in Dairy chemistry, 61-85. Ed. by P.F. Fox. Applied Science Publishers, London and New York.

SHAH P.C., MORSE G.E., 1964. Studies on albumin in " mastitic " milk : factors affecting the presence of blood-serum albumin in "Mastitic " milk. Am. J. Vet. Res., 25, 714-718.

SHERbon J.W., 1967. Rapid determination of protein in milk by Dye binding. J. Assoc. Off. Anal. Chem., 50, 542-547.

Sherbon J.W., 1974. Pro-milk method for the determination of protein in milk by Dye binding. J. Assoc. Off. Anal. Chem., 57, 1338-1341.

SHIPE W.F., 1984. Fluorimetric methods: Applications and limitations Challenges to contemporary dairy analytical techniques. The royal society of chemistry, Burlington House, London, 49, 167-178.

Smith A., Chesworth J.M., Henderson G.D., Rodway R.G., 1979. Use of Laurell electrophoresis for the quantitative measurement of albumin in mastitic milk. J. Dairy Res., 46, 547-550.

SNoEREN T.M.H., VAN RIEL J.A.M., 1979. Milk proteinase, its isolation and action on $\alpha_{\mathrm{S} 2}$ and $\beta$-casein. Milchwissenschaft, 34, 528-531,

Tessier H., Rose D., Marier J.R., 1963. Turbidimetric method for estimating sum of $\beta$ and K-caseins in whole casein. J. Dairy Sci., 46, 651-655.

UDY D.C., 1956. A rapid method for estimating total protein in milk. Nature, 178, 314-315.

URBAN W.C., 1971. Modification of the Kjeldahl nitrogen determination method. Anal Chem., 43, 300-301.

Wang P.T., Stone W.K,. 1967. Automatic Dumas procedure for nitrogen in milks products. J. Dairy Sci., 50, 937-938.

WOLFSCHOON A.F., VARGAS O.L., 1977. Formol titration for the determination of the protein content in raw and pasteurized milk. Rev. Inst. Lacticinios Candido Tostes, 32, 3-13.

WolfSCHOON A.F., VARGAS O.L., 1978. Reaction mechanism of milk protein determination by formaldehyde titration. Milchwissenschaft, 33, 480-482.

Yvon M., Van Hille I. Pélissier J.P., Guilloteau P., Toullec R., 1984. In vivo milk digestion in calf abomasum. II. Milk and whey proteolysis. Reprod. Nutr. Dev., 24, 835-843. 